\title{
UtLhคзu乙 uกฎกкৎ
}

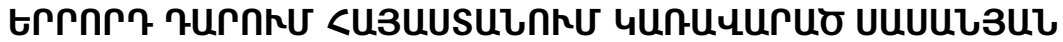

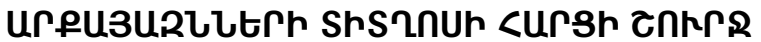

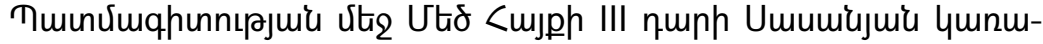

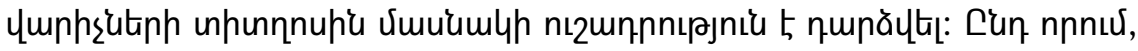

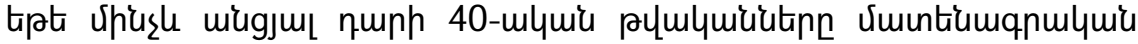

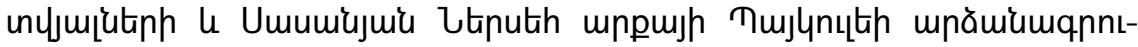

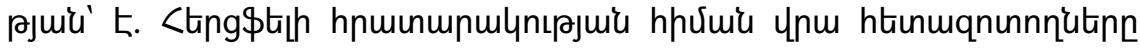

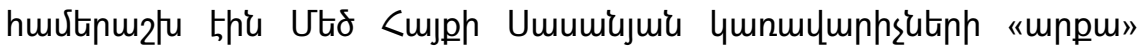

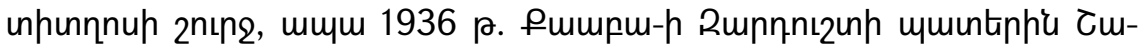

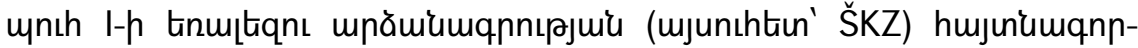

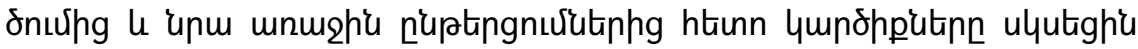

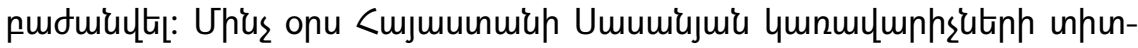

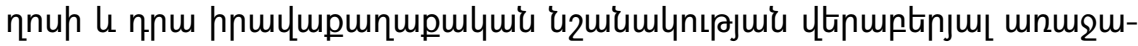

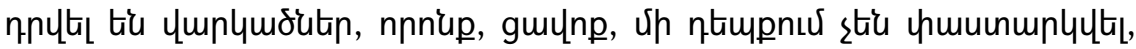

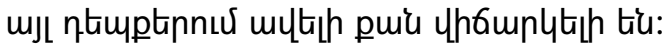

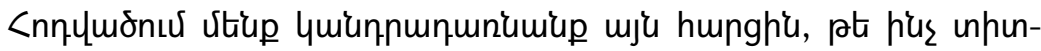

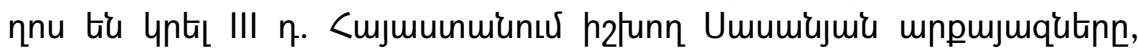

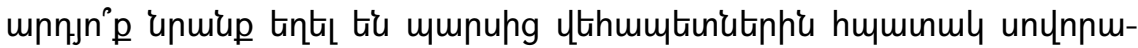

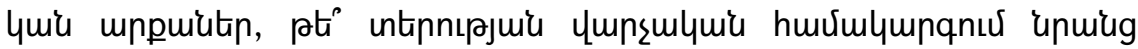

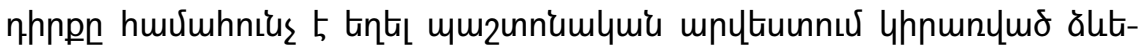

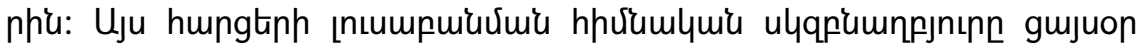

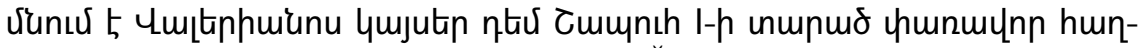

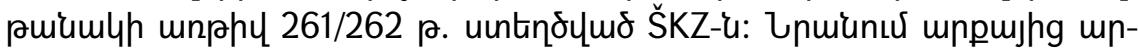

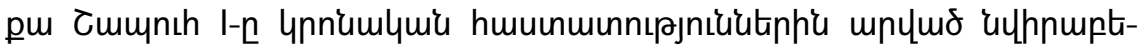

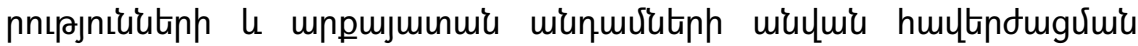

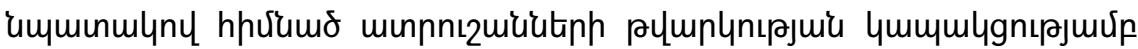

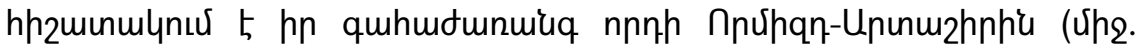

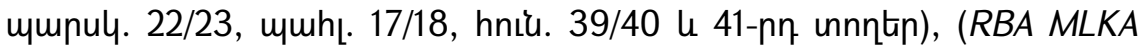




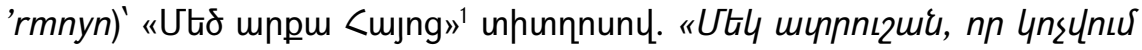

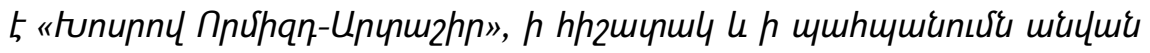

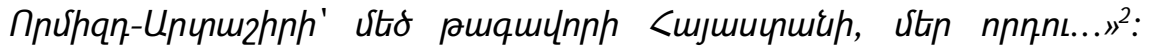

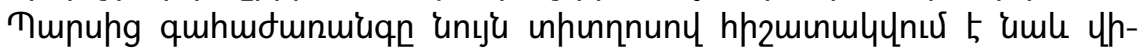

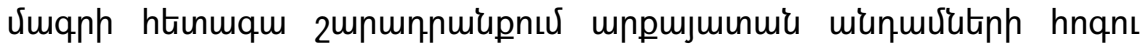

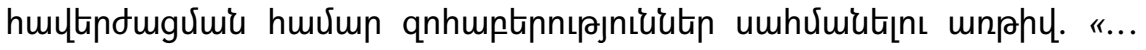

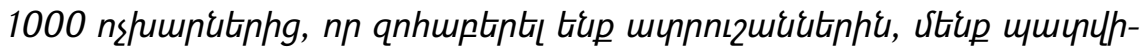

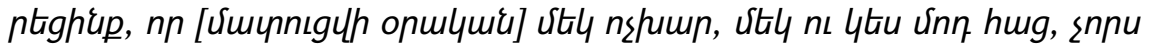

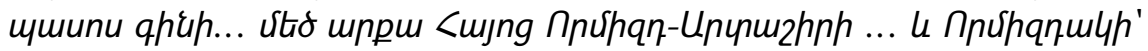

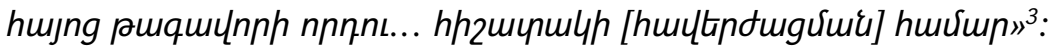

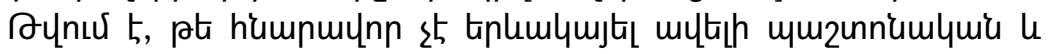

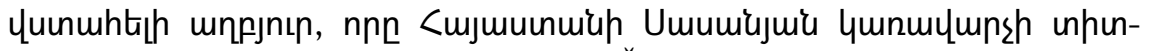

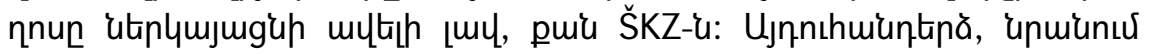

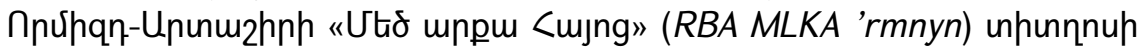

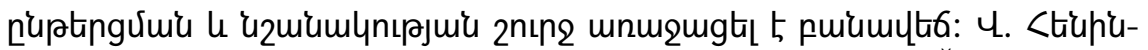

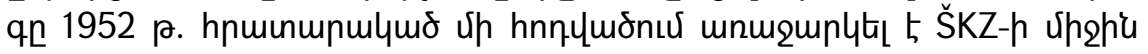

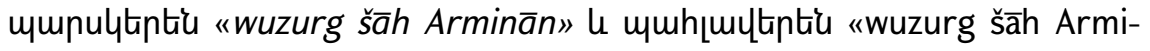

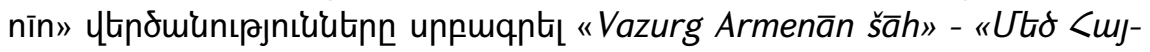

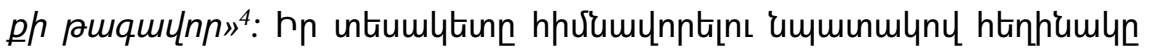

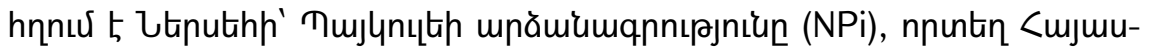

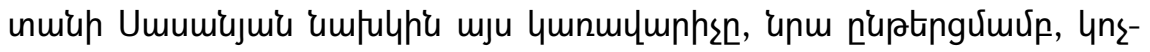
Чư 5 «Vazurg Armenān šăh»:

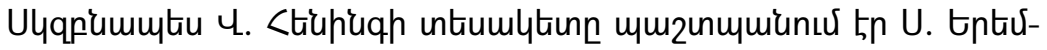

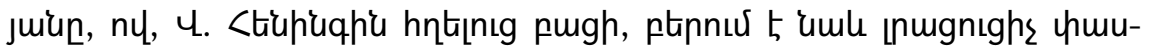

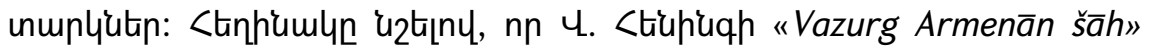

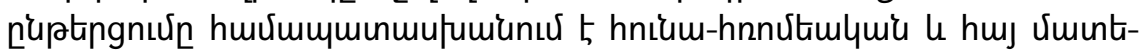

${ }^{1}$ Uhqh'u umunultintü' wuzurg šāh Arminān, umupplutintư' wuzurg šāh Arminīn,

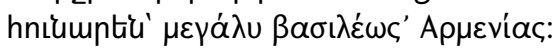

2 Honigmann E. et Maricq A., Recherches Sur les Res Gestae divi Saporis, Bruxelles, 1953, pp. 40-41.

${ }^{3}$ Unıju untinnư, t52 48, 50:

${ }^{4}$ Henning W. B., A Farewell to the Khagan of the Aq-Aqatärān, The Bulletin of the School of Oriental and African Studies, 1952, XIV/3, p. 517.

${ }^{5}$ Unıju untinnu, t2 517, duiu. 4: 


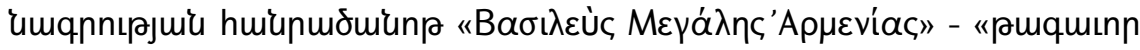

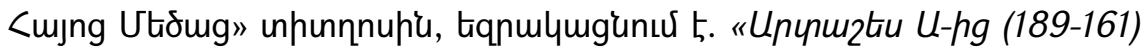

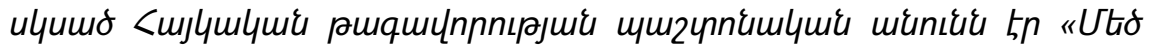

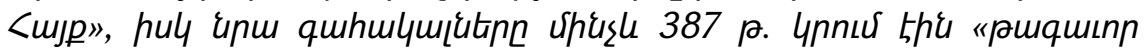

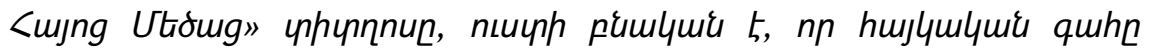

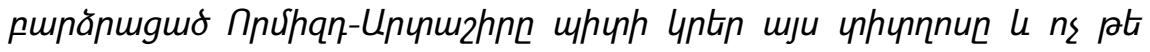

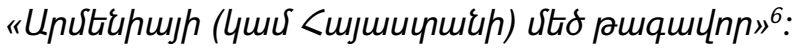

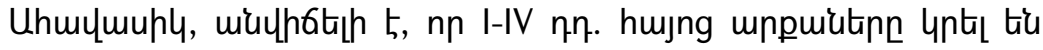

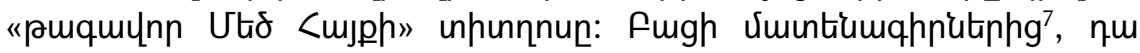

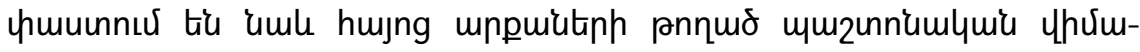

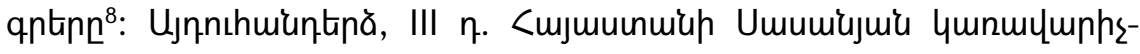

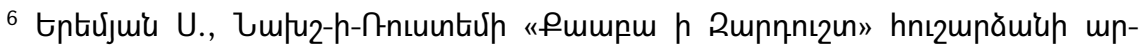

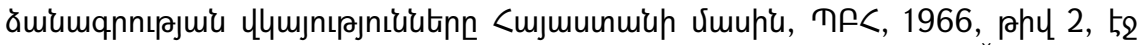

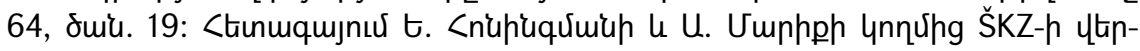

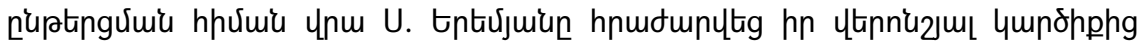

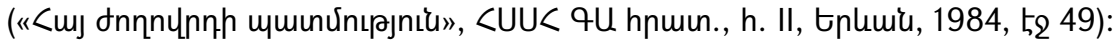

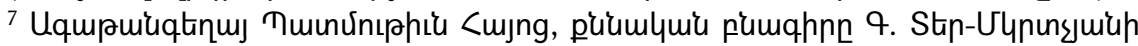

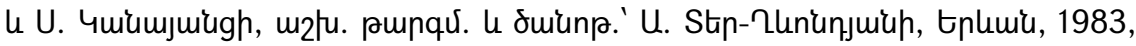

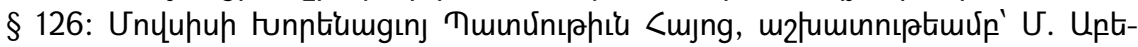

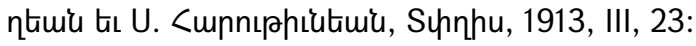

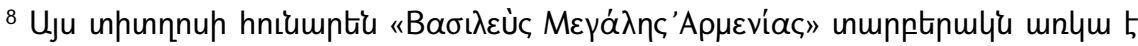

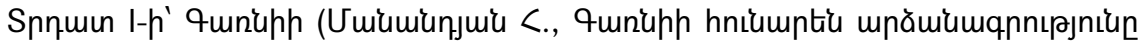

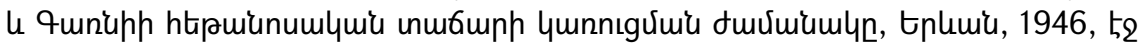

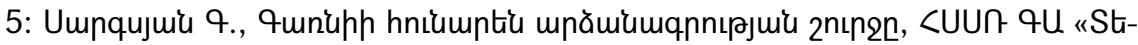

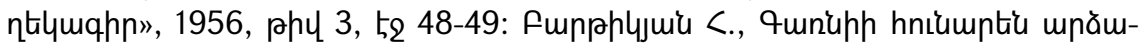

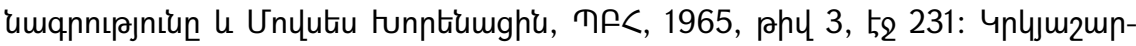

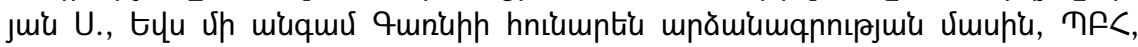

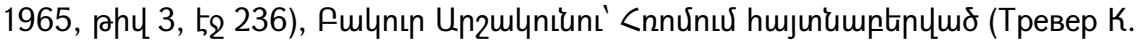
В. "Очерки по истории культуры древней Армении (II в до н.э. - IV в н.э.)", Москва-Ленинград, 1953, стр. 237-242) U Spquin II-h quú Spquin III-h' Uщишишup (Ростовцевъ М., Апаранская греческая надпись царя Тиридата, С.-

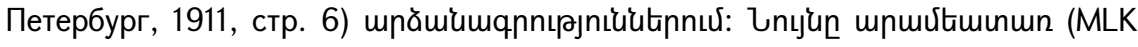

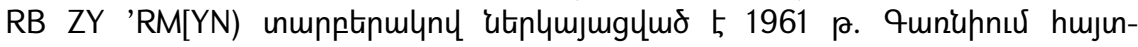

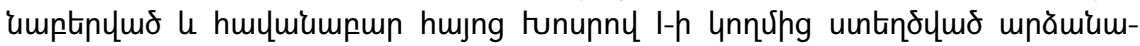

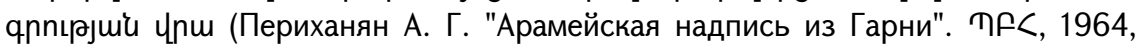
рүय 3, стр. 123): 


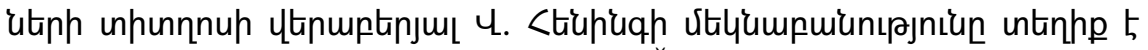

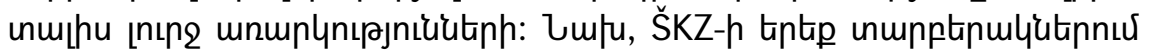

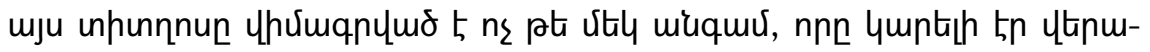

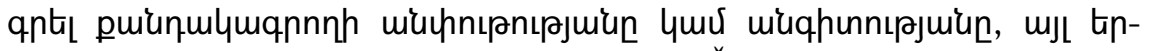

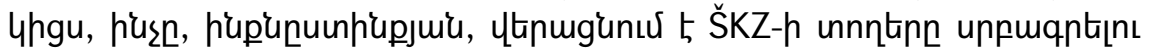

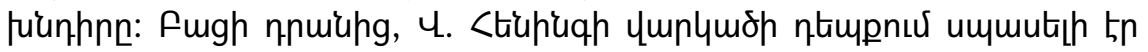

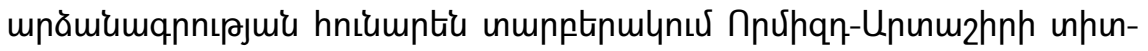

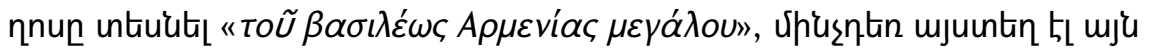

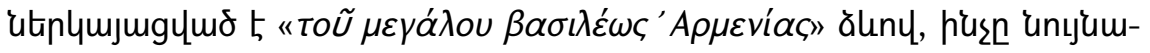

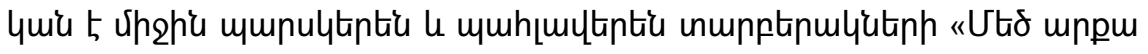

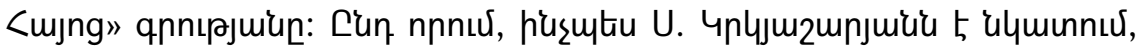

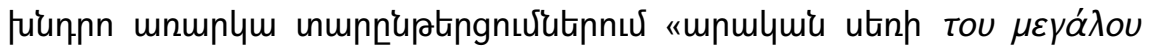

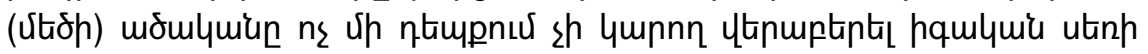

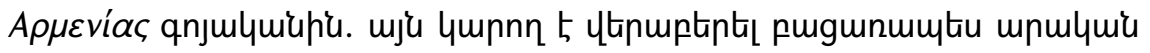

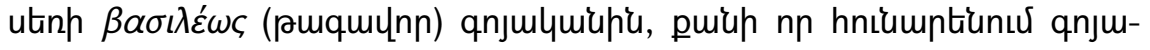

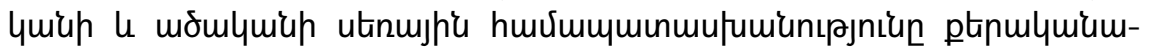
4wi umunumunh optiup 5$)^{9}$ :

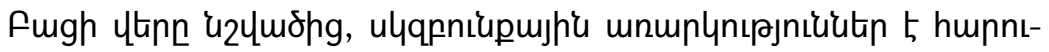

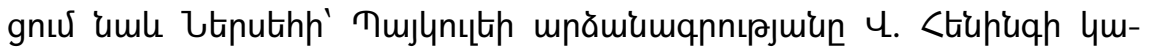

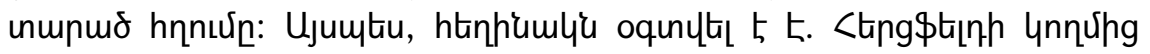

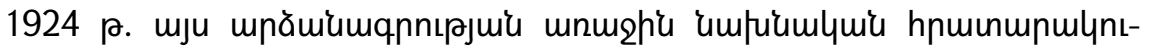

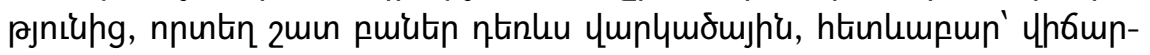

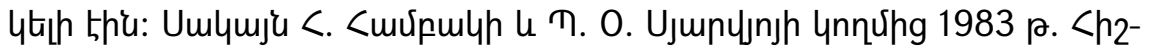

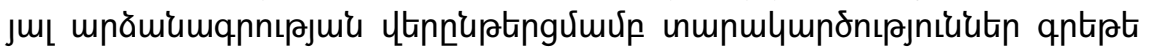

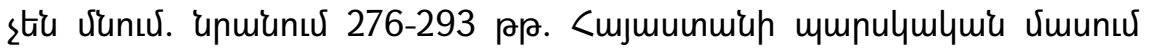

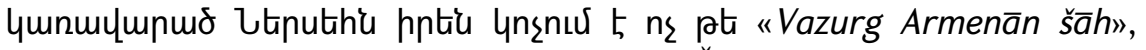

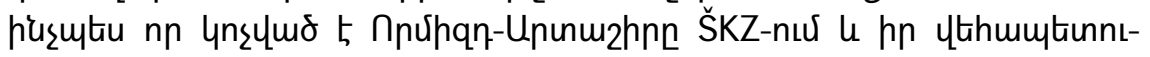

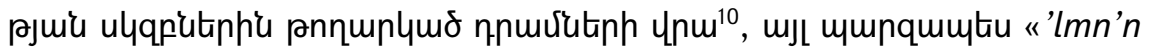

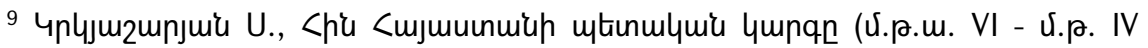

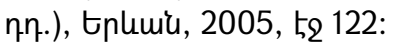

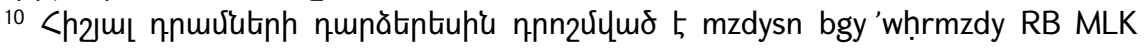

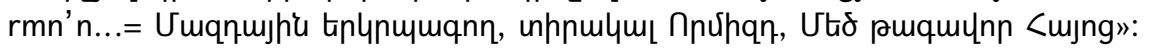

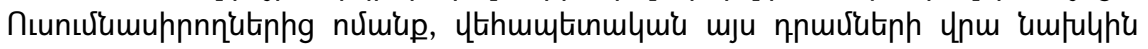

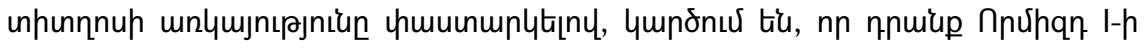




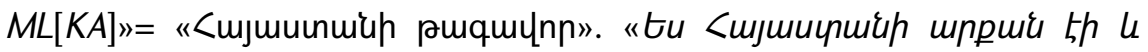

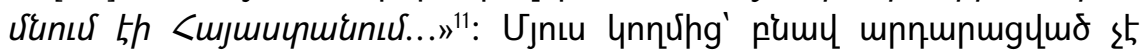

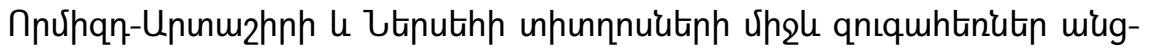

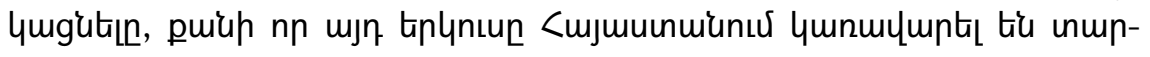

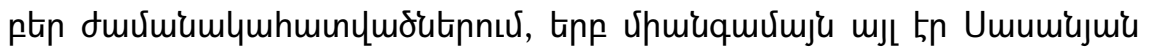

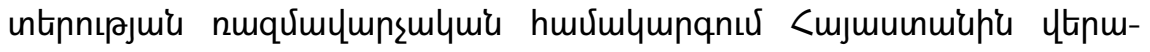

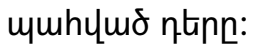

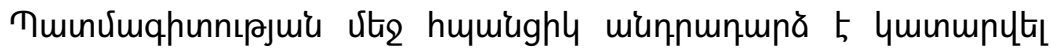

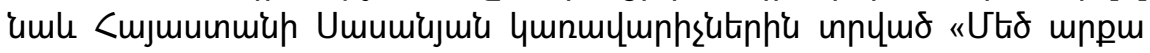

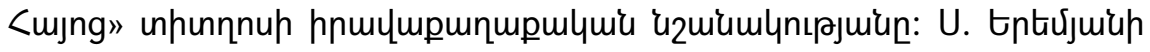

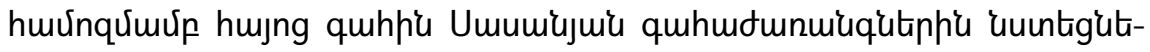

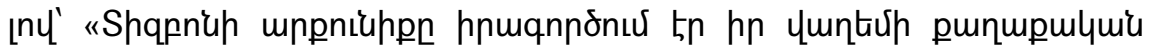

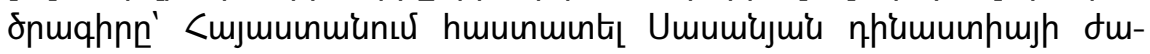

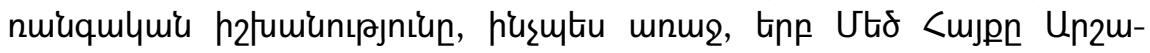

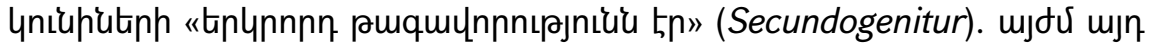

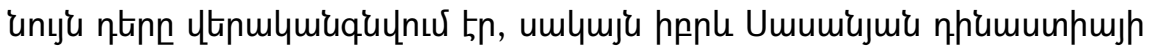

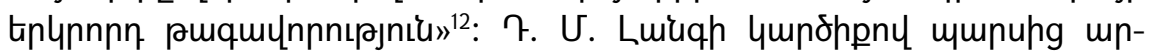

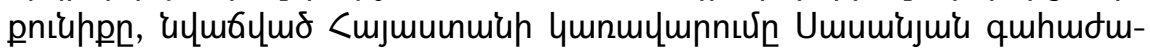

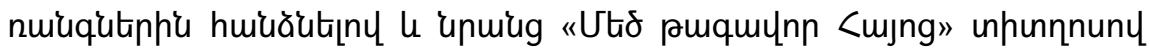

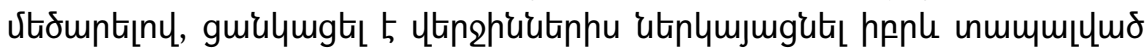

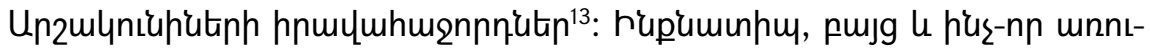

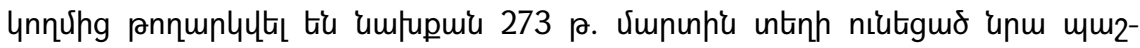

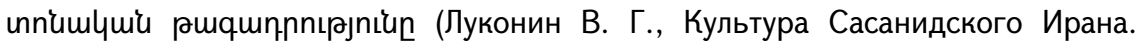

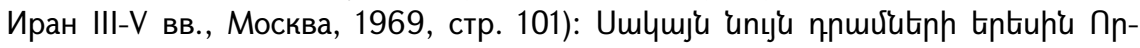

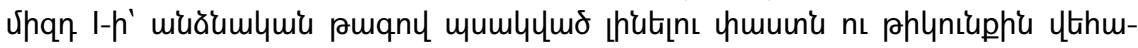

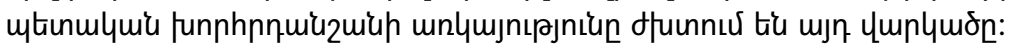

$"$ Humback H. and Skjaervø P. O.,The Sasanian Inscription of Paikuli, Part 3.1.,

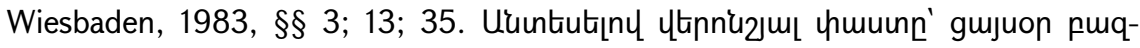

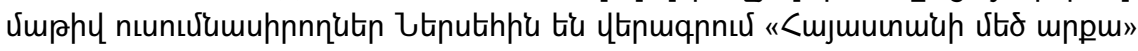

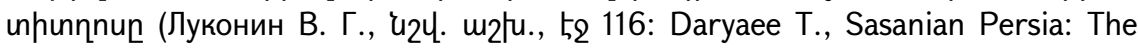
Rise and Fall of an Empire, London, New York, 2009, pp. 10-11; Дашков С. Б., Цари царей: Сасаниды, Москва, 2008, стр. 89):

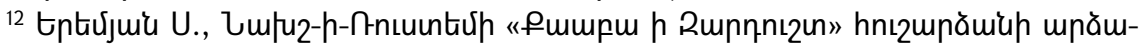

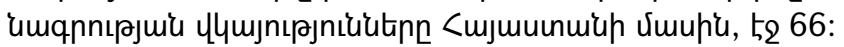

${ }^{13}$ Lang D. M., Iran, Armenia and Georgia,The Cambridge History of Iran, Ed.by I. 


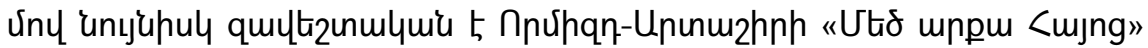

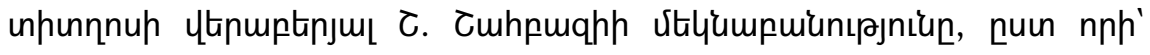

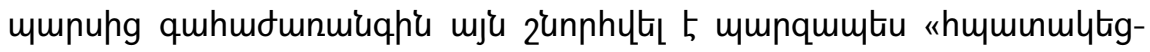

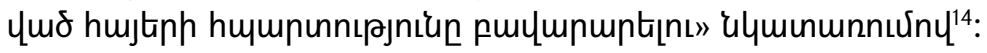

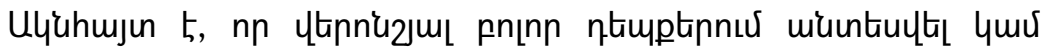

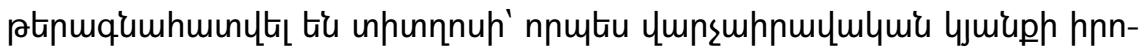

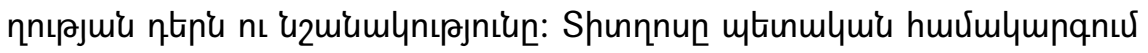

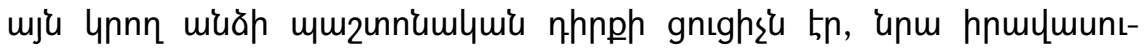

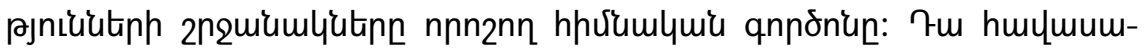

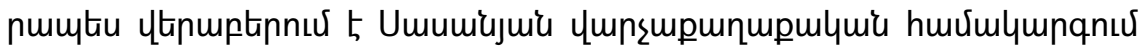

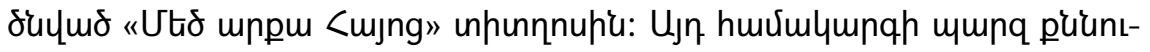

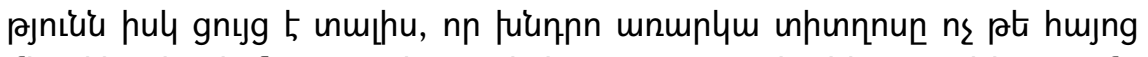

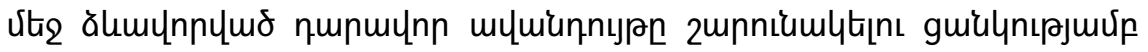

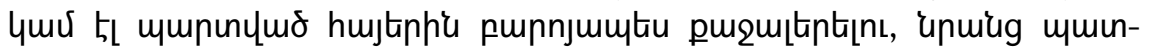

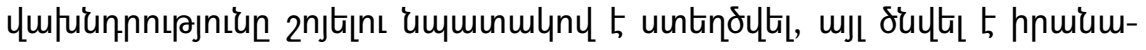

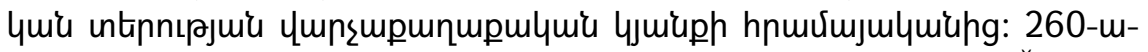

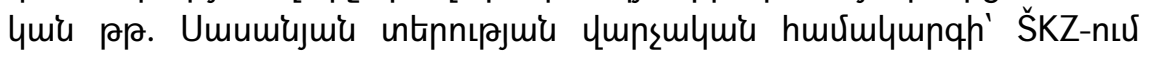

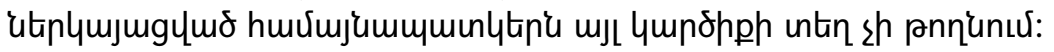

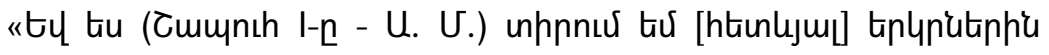

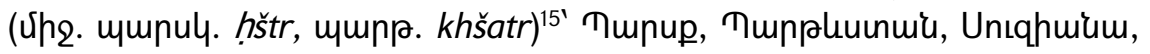

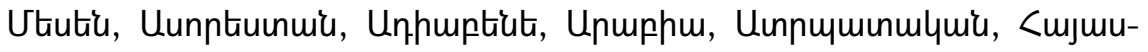

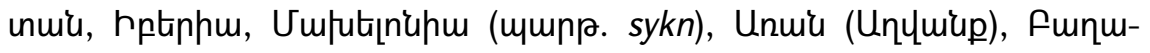

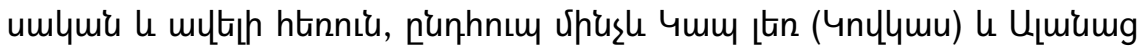

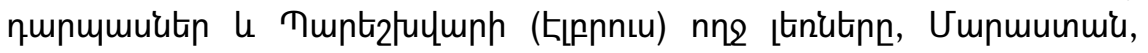

Gershevitch, vol. 3(I), 2000, p. 517.

${ }^{14}$ Shahbazi Sh., Shapur I i, History, Encyclopedia Iranica, Originally Published: July 20, 2002.

15 U. Fulyn «ḥštrdr»-n punquimiunuर 5 "puquulnnutp»" (Back M., Die sassanidischen Staatsinschriften. Acta Iranica 18, Téhéran-Liège, 1978, p. 289), Uhǔntun \$. Jjünniu (Gignoux Ph., Clossaire des Inscriptions Pehlevies et Parthes, L., 1972

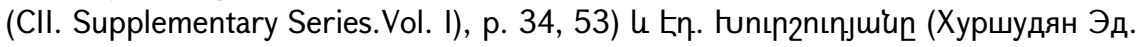
"Государственные институты Парфянского и Сасанидского Ирана". Алматы.

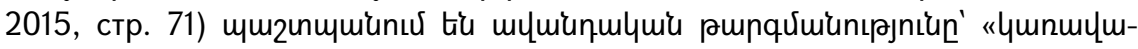
nh々": 


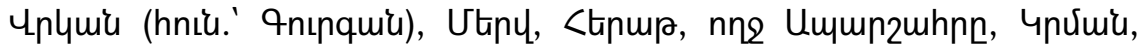

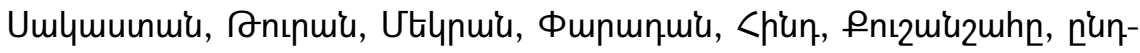

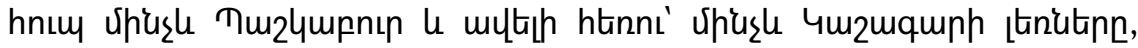

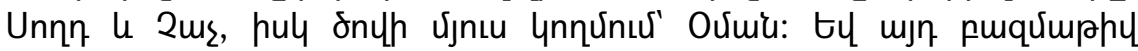

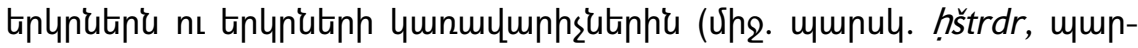

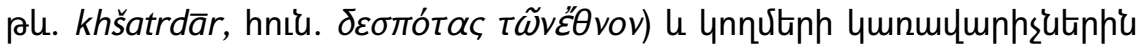

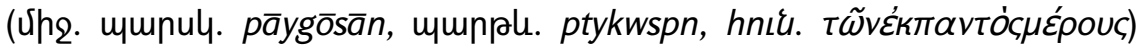

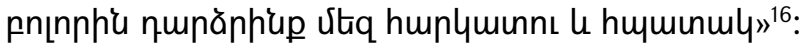

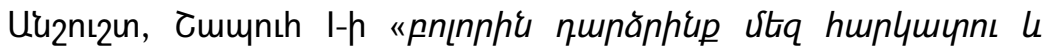

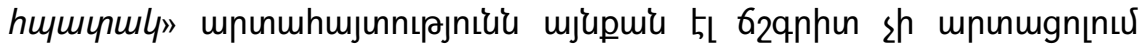

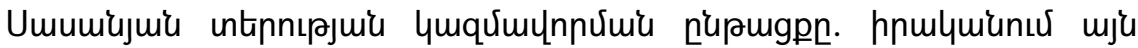

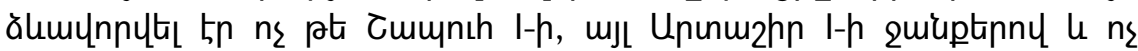

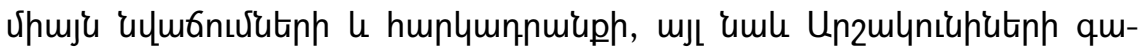

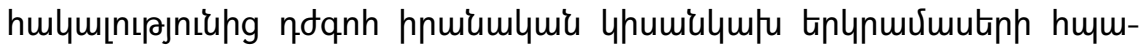

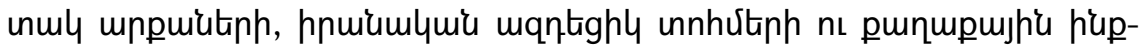

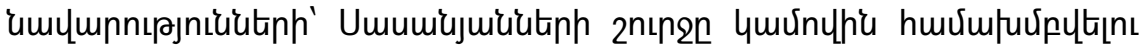

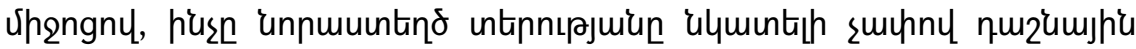

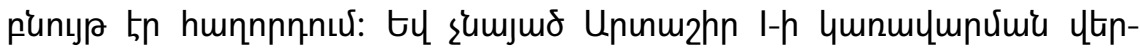

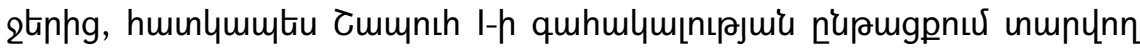

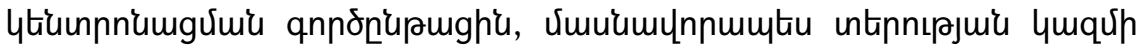

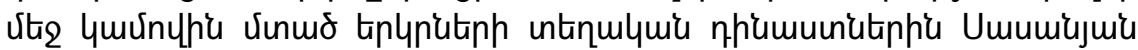

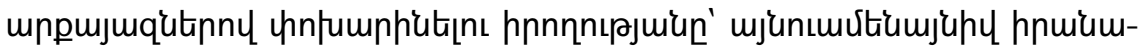

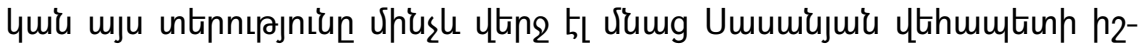

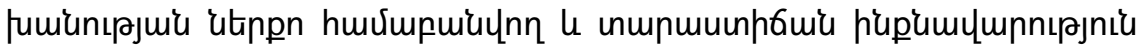

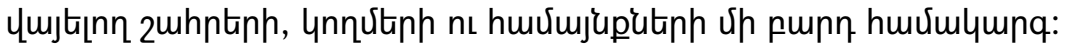

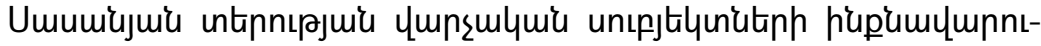

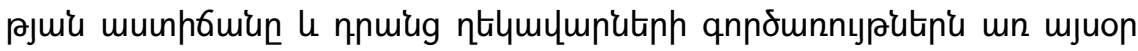

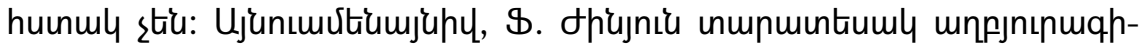

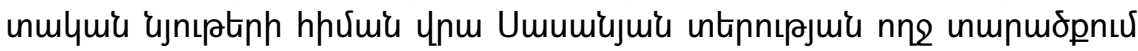

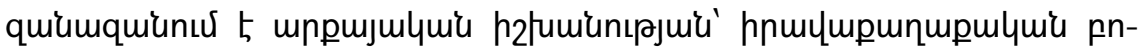

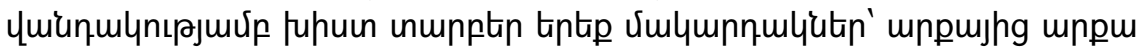

${ }^{16}$ Luvun. Sprengling M., Third century Iran, Sapor and Kartir, Chicago, 1953, pp. $14-15$. 


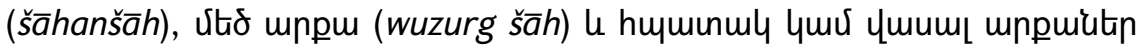

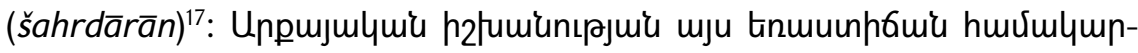

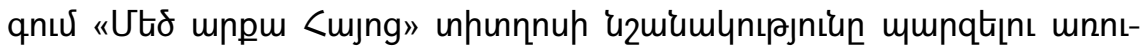

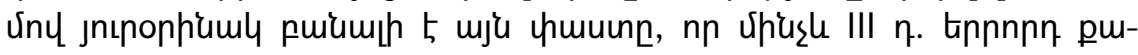

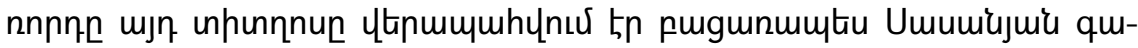

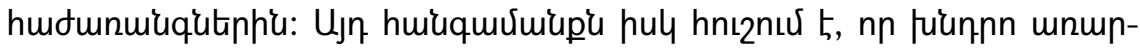

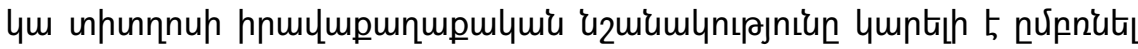

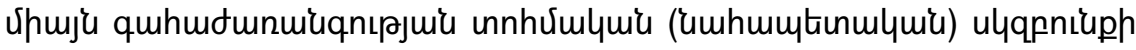

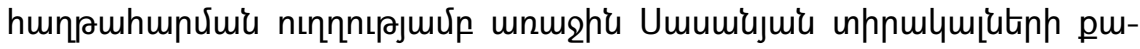

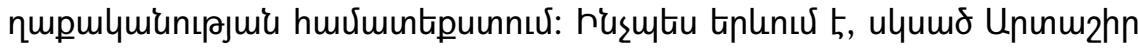

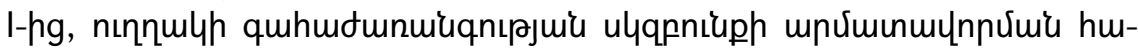

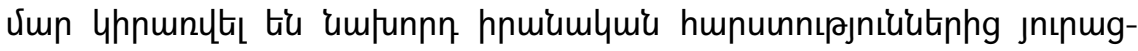

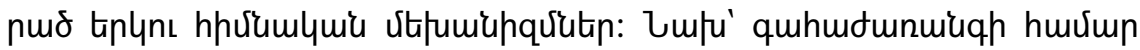

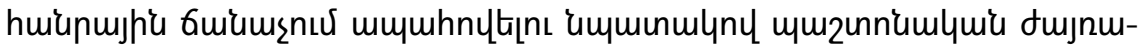

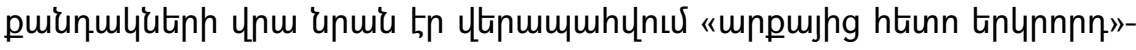

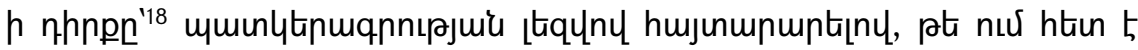

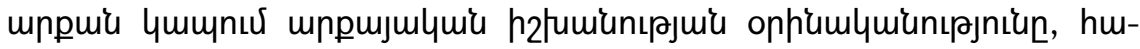

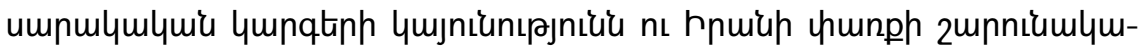

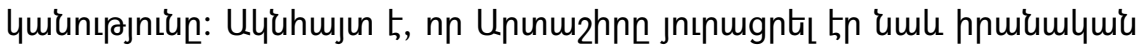

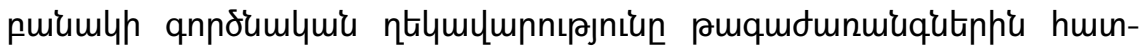

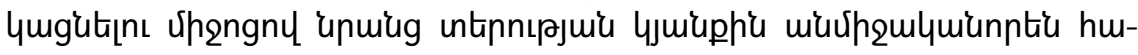

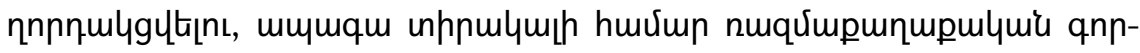

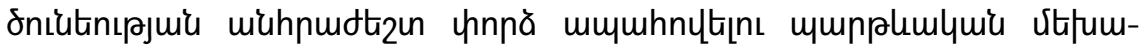

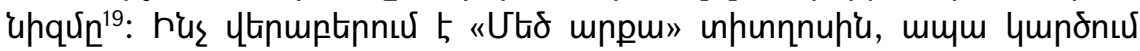

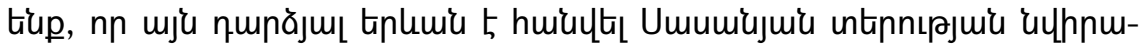

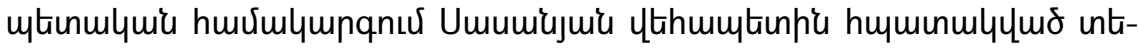

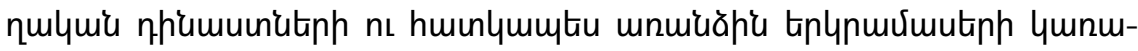

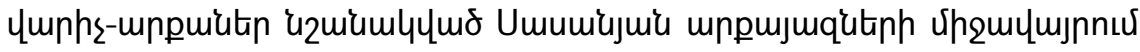

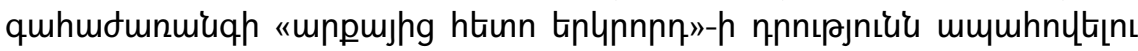

\footnotetext{
17 Gignoux Ph. Court and Courtiers II. In the Parthian and Sasanian Periods, Elr, 1993, Vol. VI, Fasc. 4, p. 360.

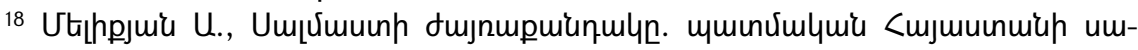

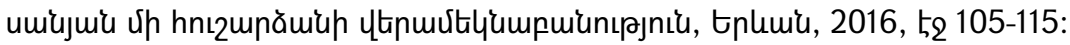
${ }^{19}$ Unıju untinnux, to 106-115:
} 


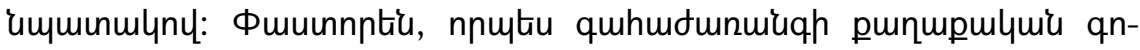

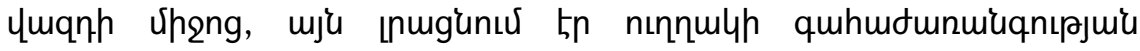

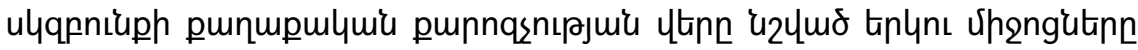

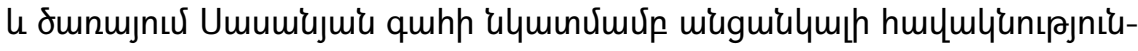
utinn luiututiniu:

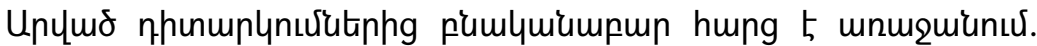

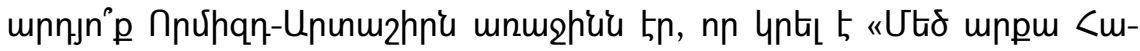

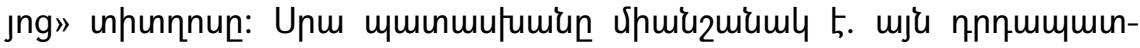

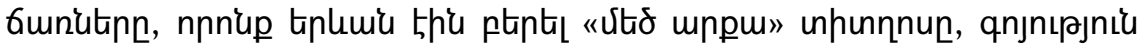

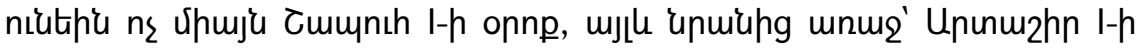

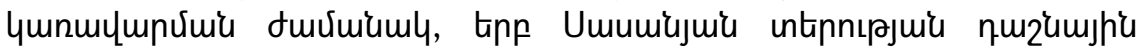

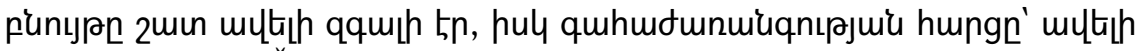

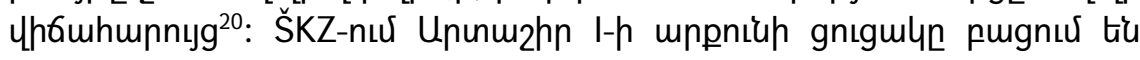
¿nnu unpuiutin (šahrdārān). «Uhw unuiup, nnnup munta tiu mppujhg

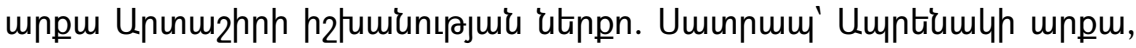

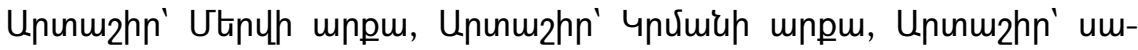

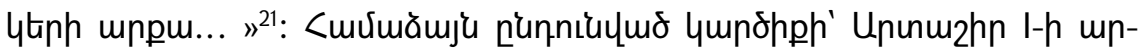

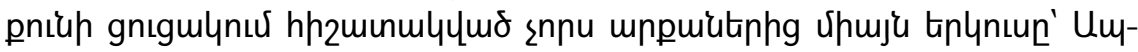

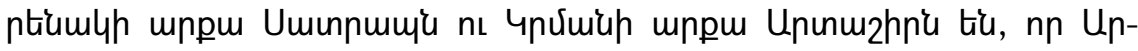

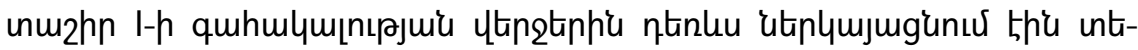

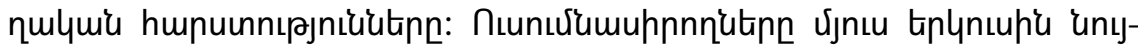

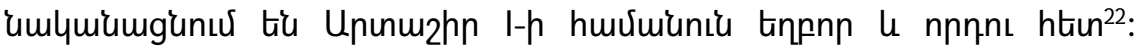

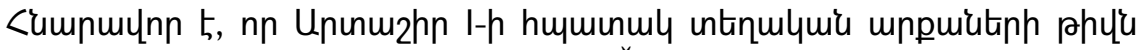

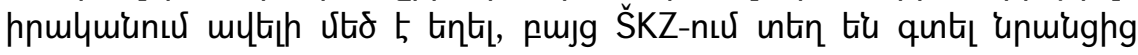

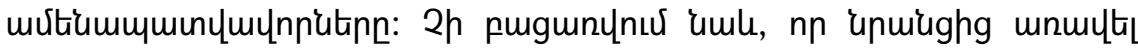

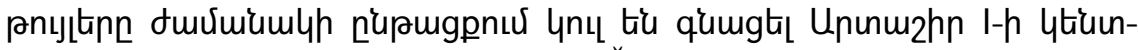

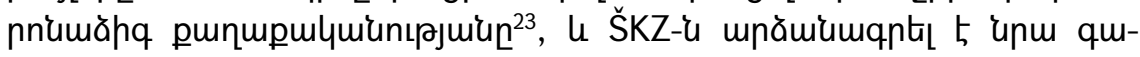

\footnotetext{
20 Unuju untinnư, $5_{2}$ 102:

${ }_{21}^{2}$ ŠKZIV, 6b. See Sprengling M., Third Century Iran..., p. 18.

${ }^{22}$ Hinz W., Altiranische Funde und Fourschungen, Berlin, 1969, S. 142; Frye R.N., The Political History of Iran Under The Sasanians, CHI, vol. 3 (I), Cambridge, 2000, p. 120):

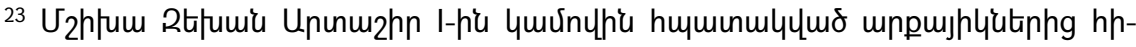

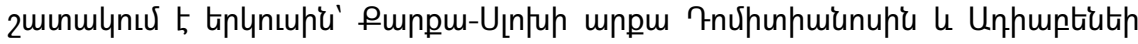




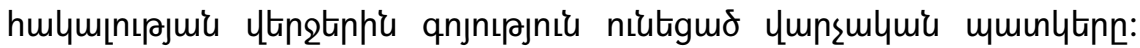

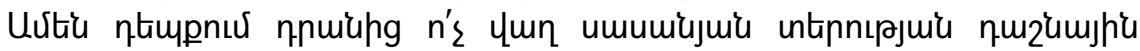

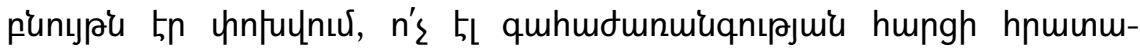

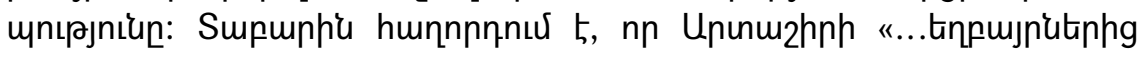

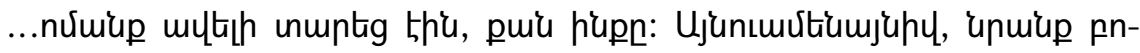

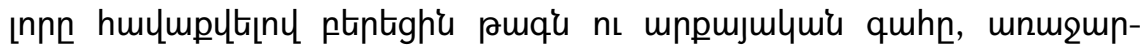

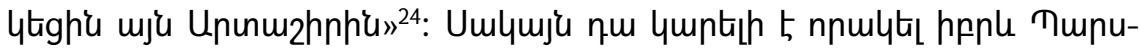

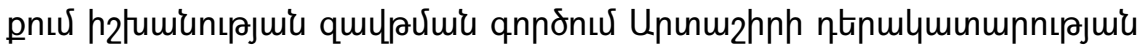

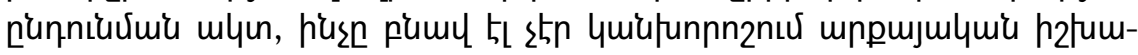

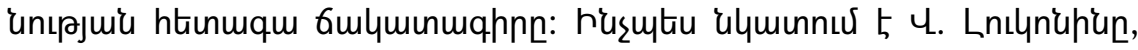

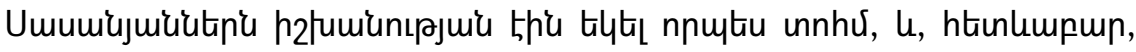

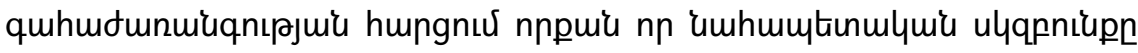

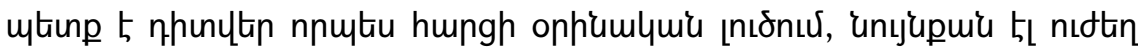

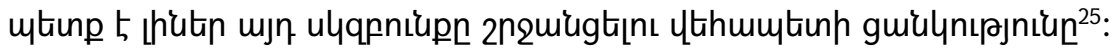

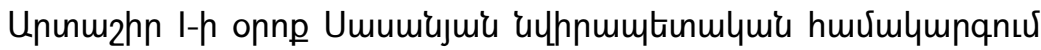

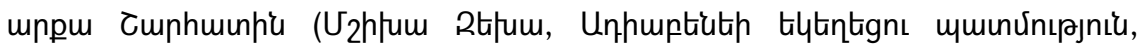

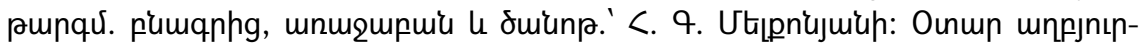

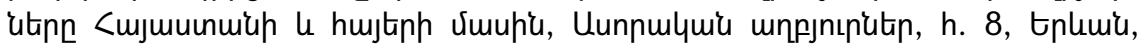

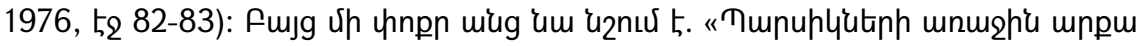

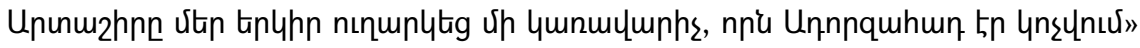
(unuju untnnuu, t. 84):

24 The History of al-Tabarī (Ta'rīkh al-rusul wa'l-mulūk): The Sāsānids, the Byzantines, the Lakhmids and Yemen. Transl. and annotated by C. E. Boswarth, Albany, New York, 1999, pp. 8-9.

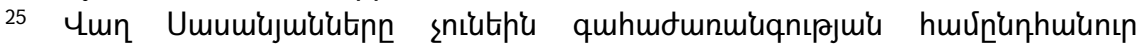

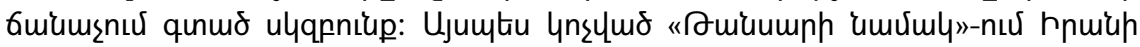

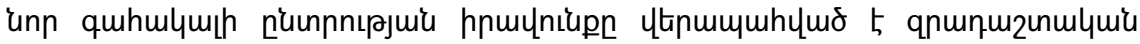
puhuiumjumbtinn (mowbedān mowbed), qunumutiunh (dabīrbed, dibīruft) $u$

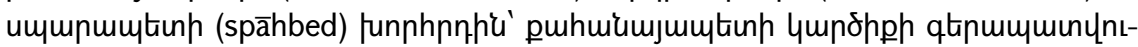

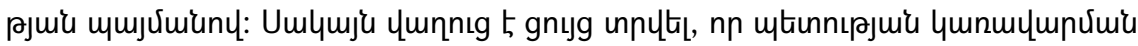

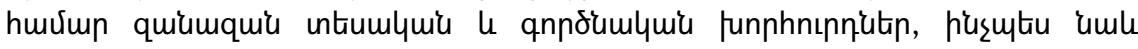

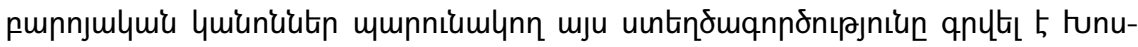

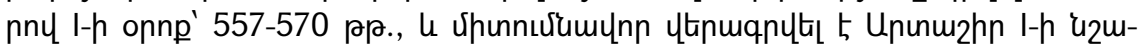

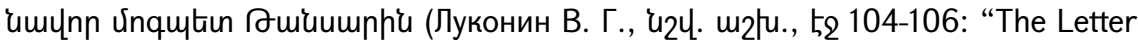
of Tansar", translated by M. Boyse, Roma, 1968): 


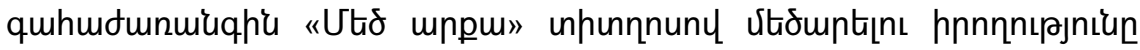

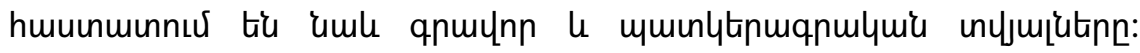

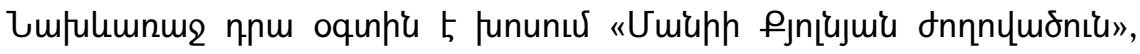

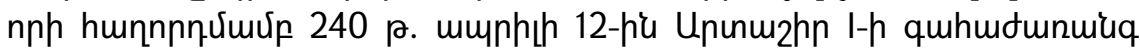

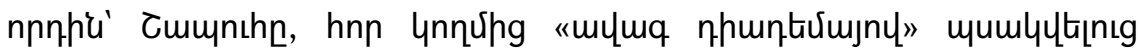

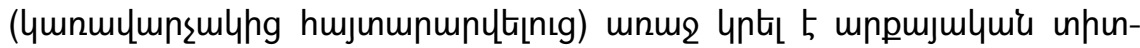

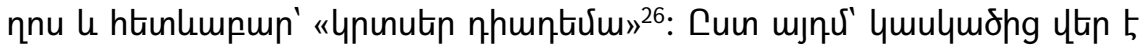

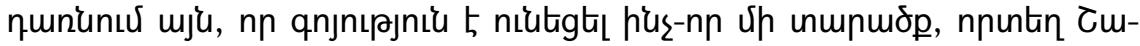

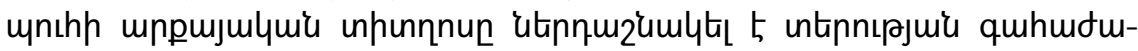

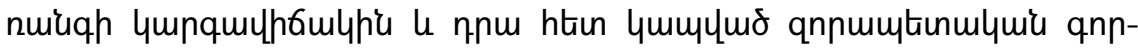

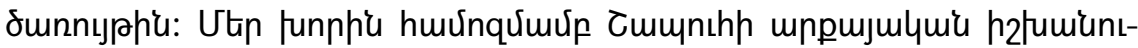

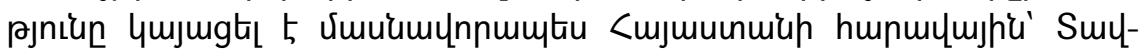

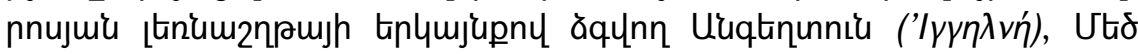

${ }^{26}$ Herichs A. and Koenen L., Ein grieshischer Mani-Codex, Zeitschrift für Papyrologie und Epigraphik V, (Bonn, 1970), S. 120; Henrichs A., The Cologne Mani Codex Reconsidered, Harvard Studies in Classical Philology, Vol. 83, 1979, pp. 339-367; Sundermann W., Studien zur kirchengeschichtlichen Literatur der iranischen Manichäer I, Altorientalische Forschungen, 1986, 13, S. 49. 乙.

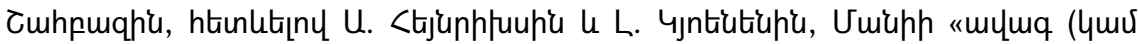

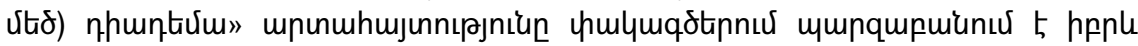

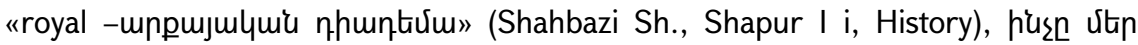

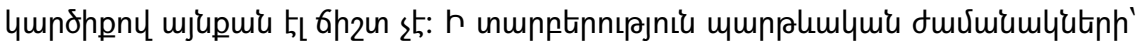

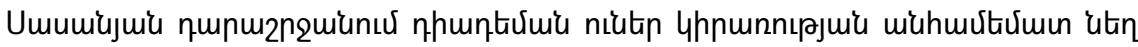

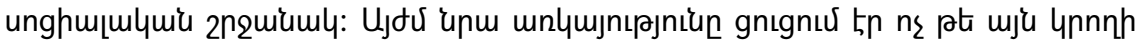

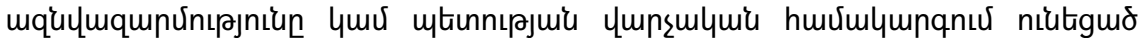

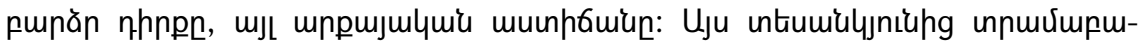

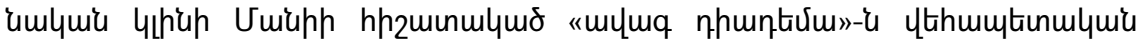

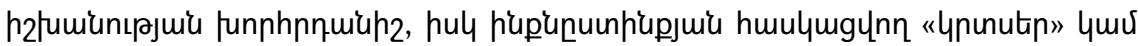

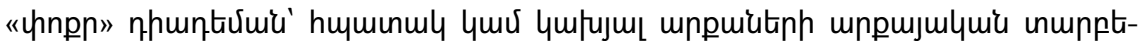

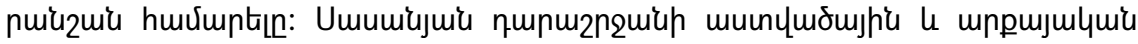

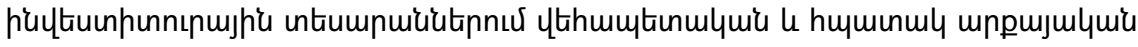

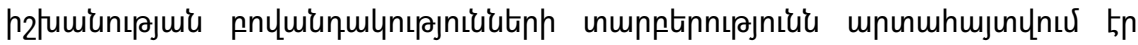

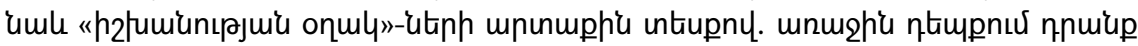

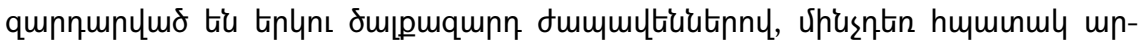

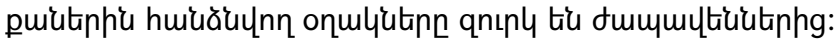




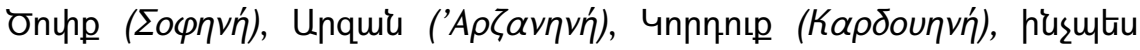

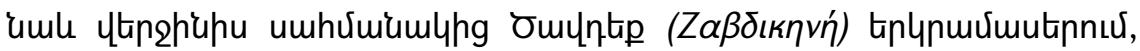

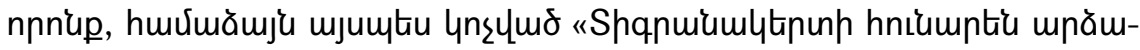

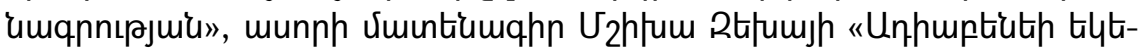

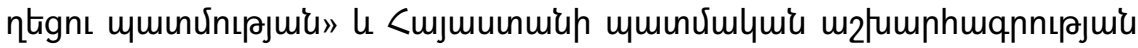

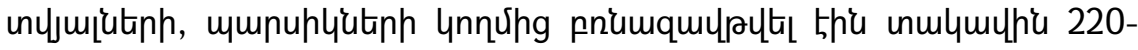

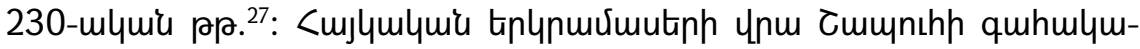

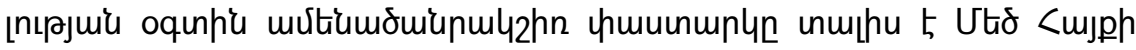

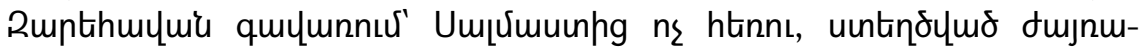

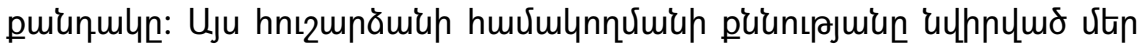

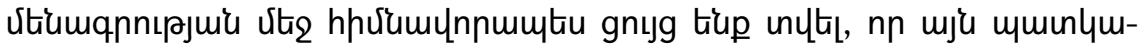

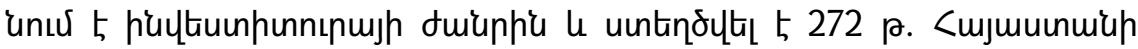

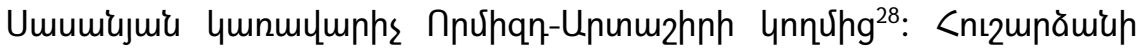

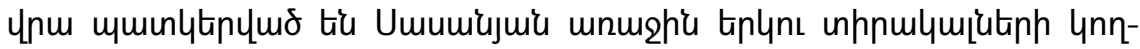

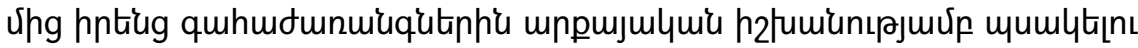

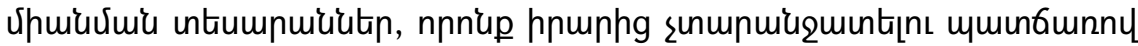

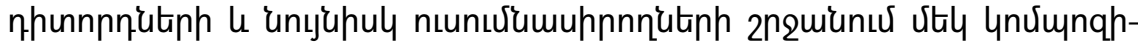

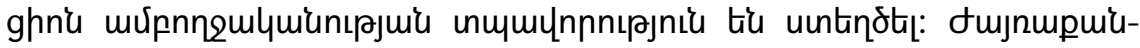

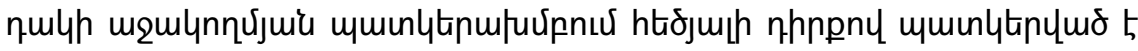

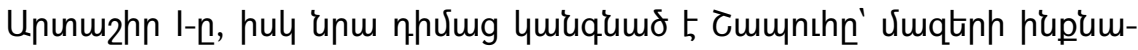

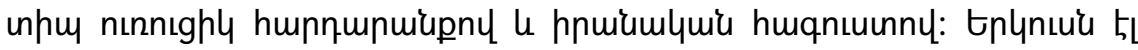

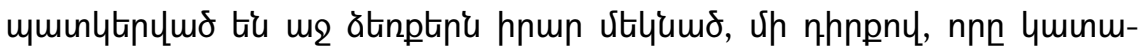

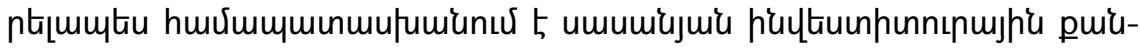

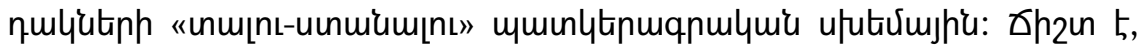

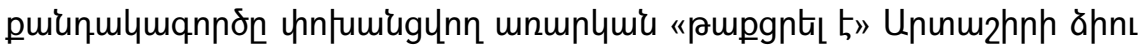

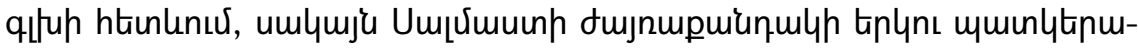

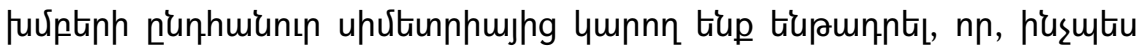

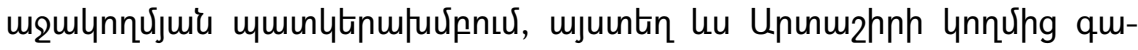

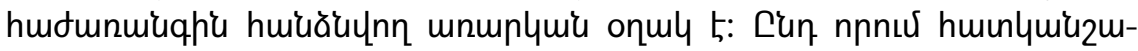

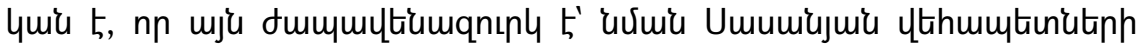

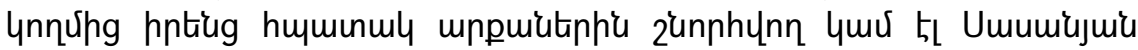

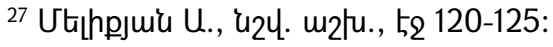

28 Unıju untnnnư, $5_{2}$ 163-166: 


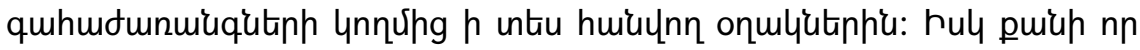

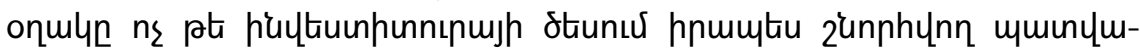

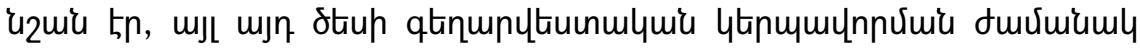

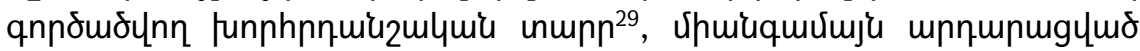

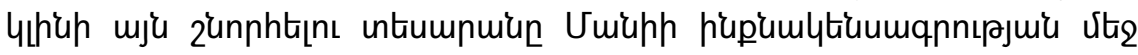

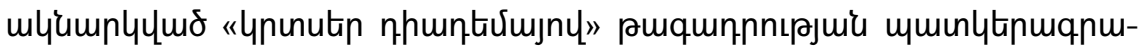
quiu huviumottpg huviunt $\mathrm{Ln}^{30}$ :

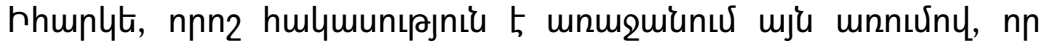

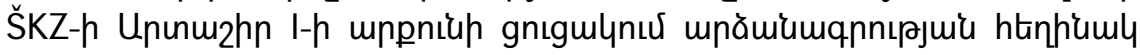

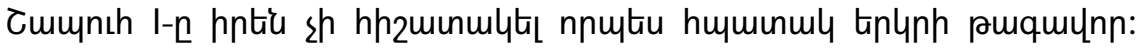

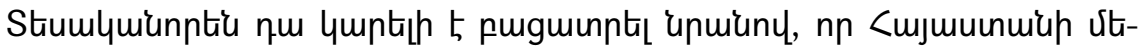

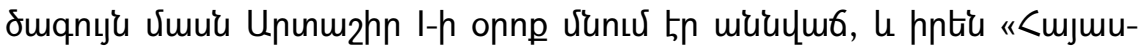

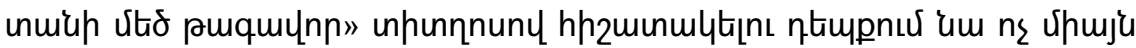

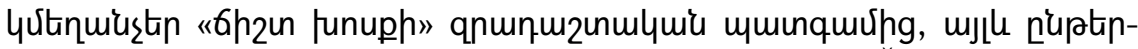

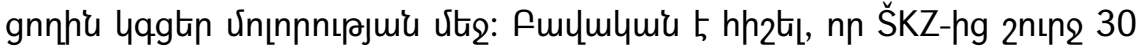

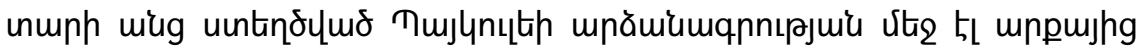

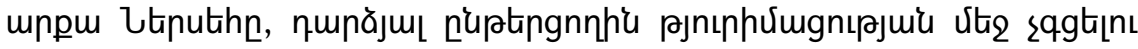

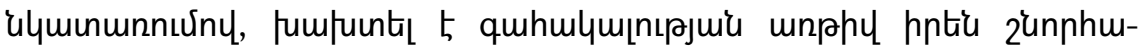

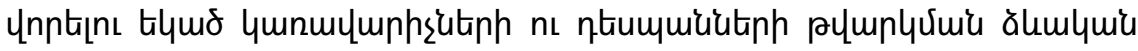

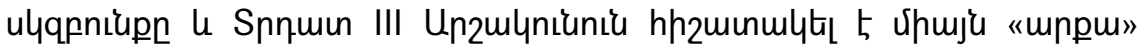

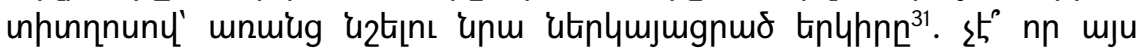

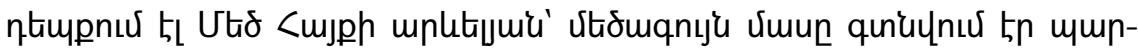

\footnotetext{
${ }^{29}$ von Gall H., The Figural Capitals at Taq-e Bostan and the Question of the socalled Investiture in Parthian and Sasanian Art, Silk Road Art and Archaeology I, 1990, p. 107.

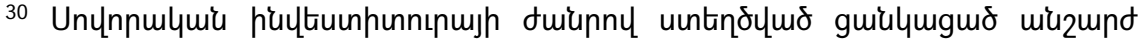

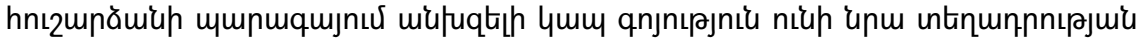

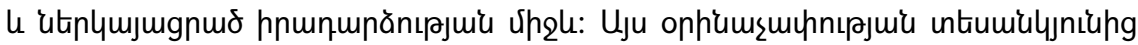

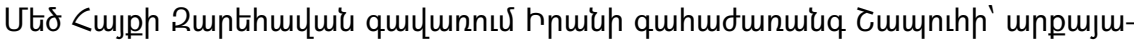

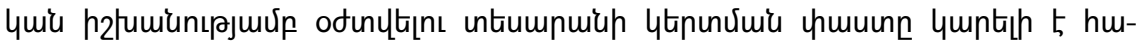

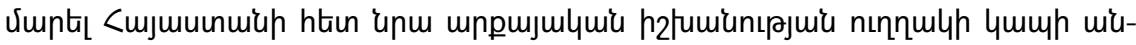

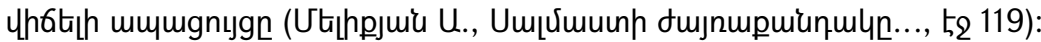

${ }^{31}$ Humbach H. and Skjaerv $\varnothing$ P.O., The Sassanian Inscription of Paikuli, Part 3.1, § 92.
} 


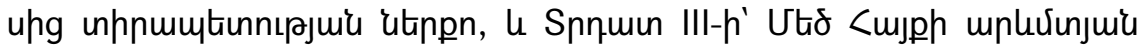

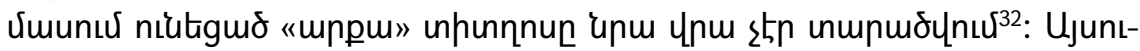

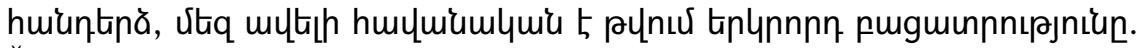

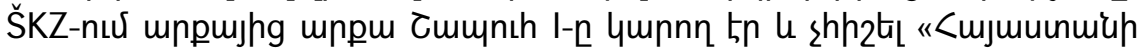

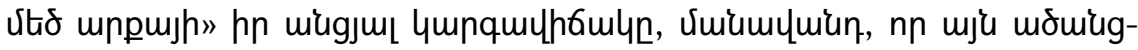
y

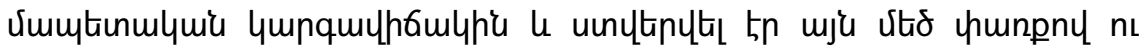

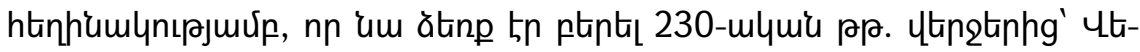

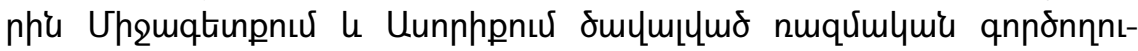

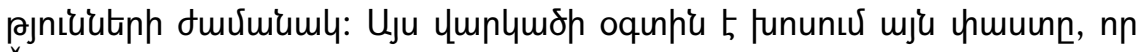

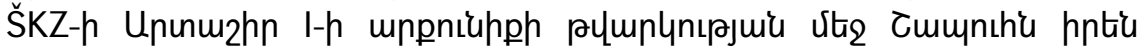

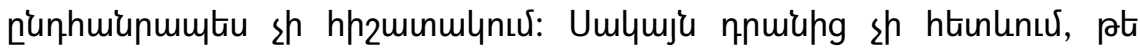

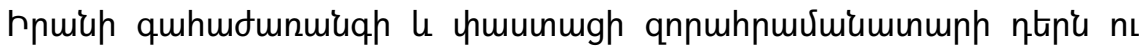

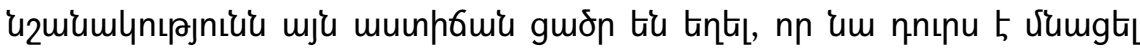

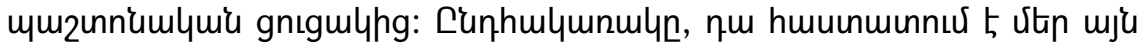

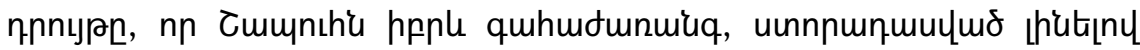

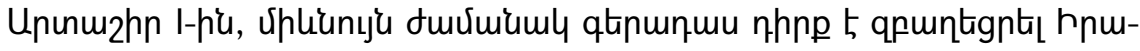

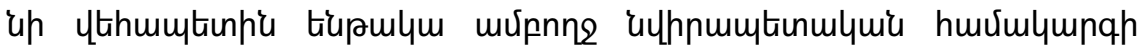

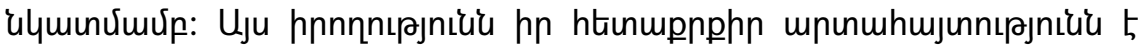

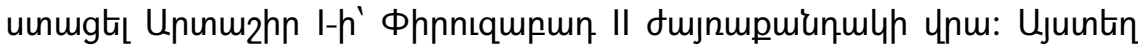

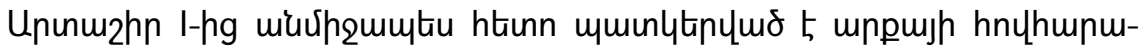

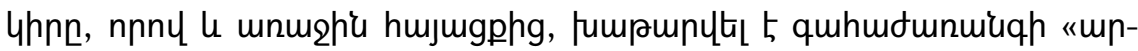

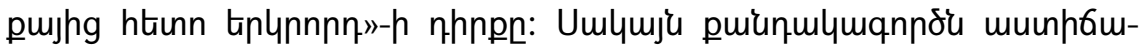

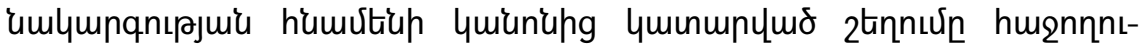

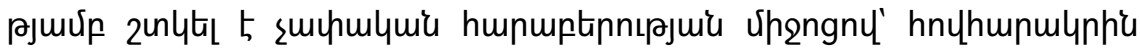

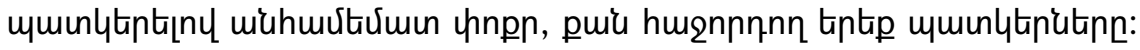

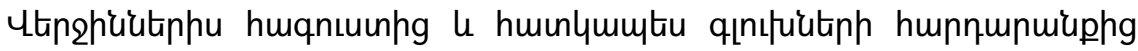

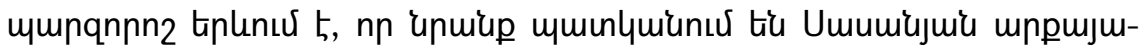

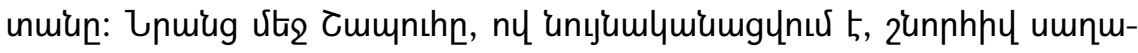

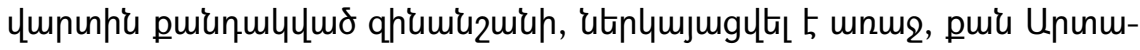

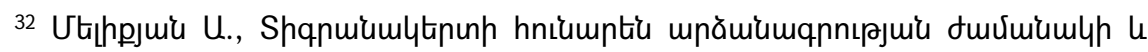

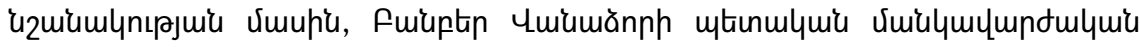
piuunhunnunh, 2008, 3, 52 142: 


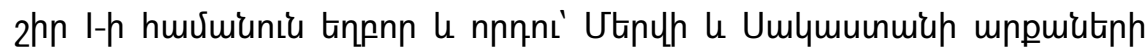

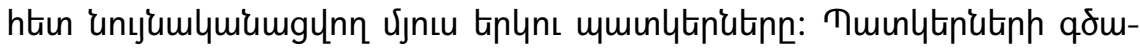

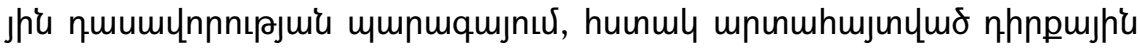
unmult

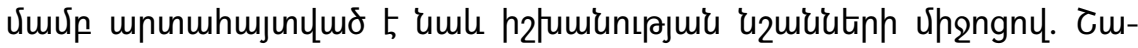

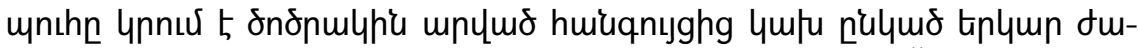

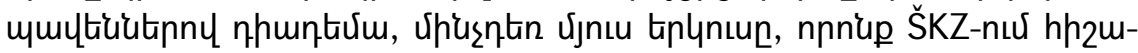

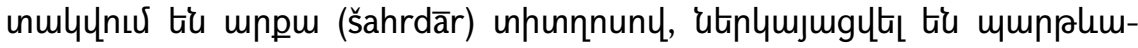

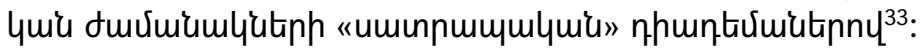

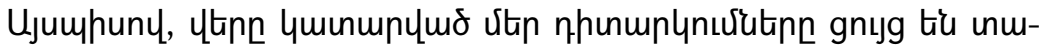

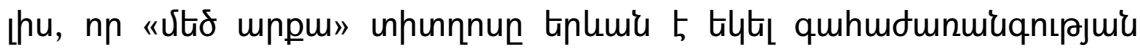

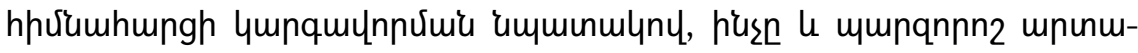

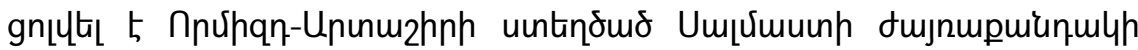

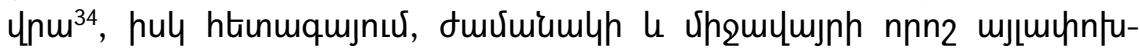

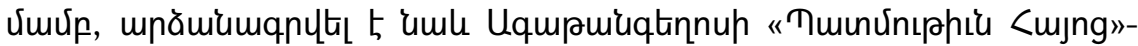

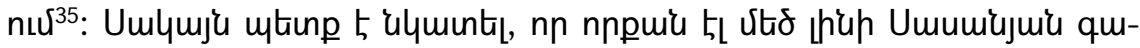

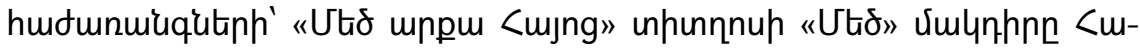

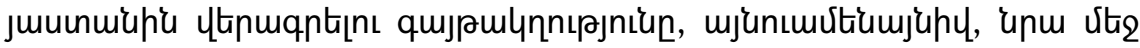

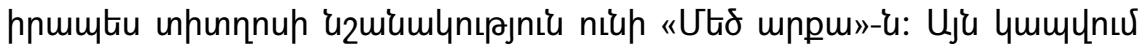

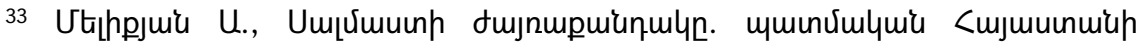

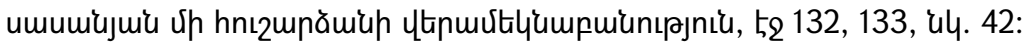

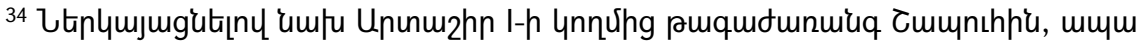

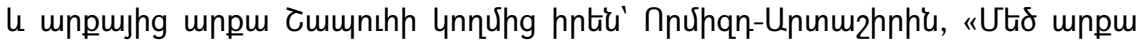

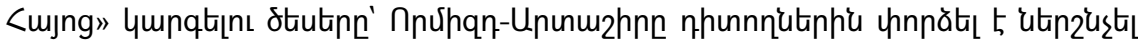

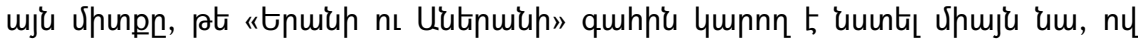

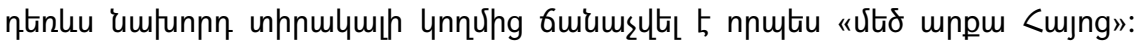

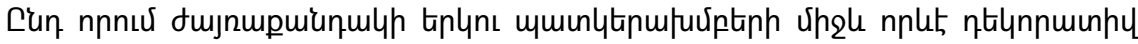

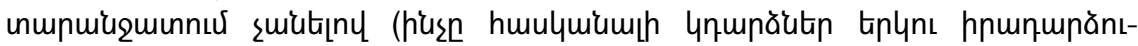

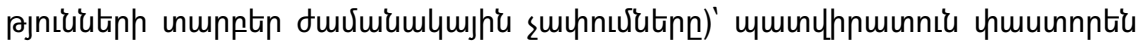

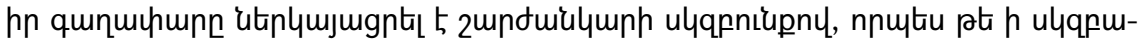

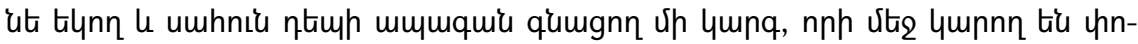

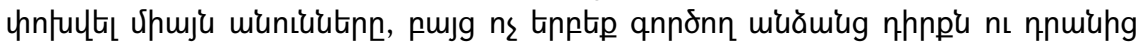

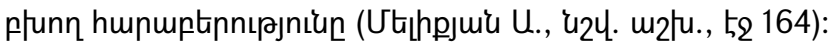

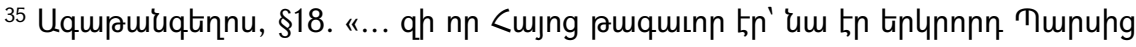
untpnıptiuiulu...»: 


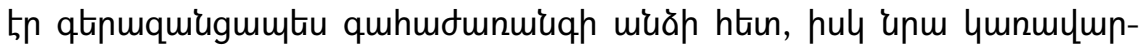

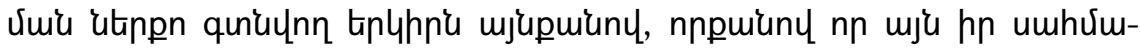

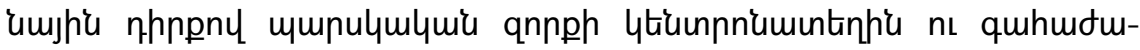

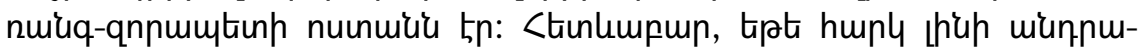

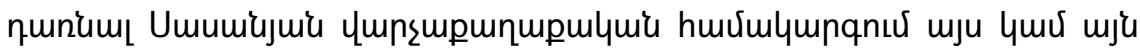

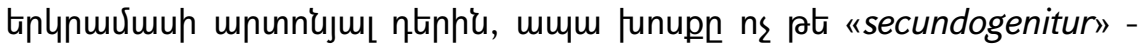

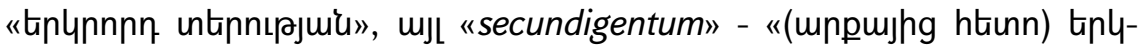

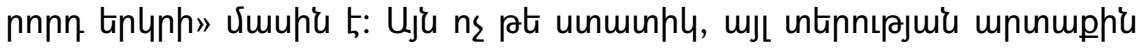

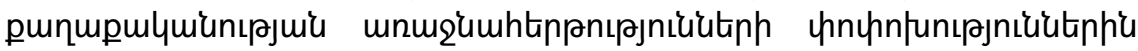

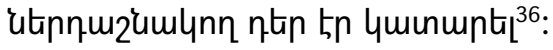

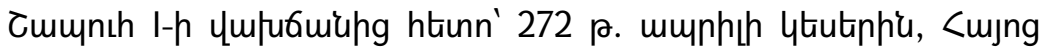

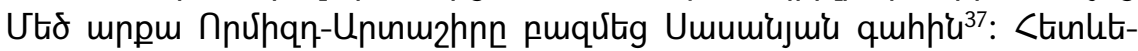

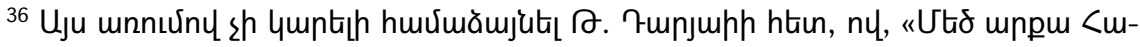

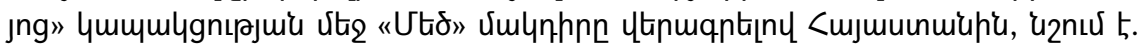

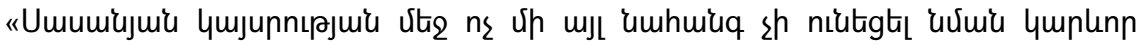
unhunnnu» (Daryaee T., Sasanian Persia: The Rise and Fall of an Empire, LondonNew York, 2009, p. 8):

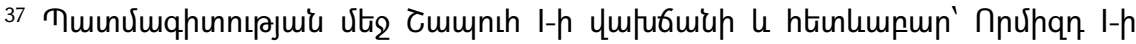

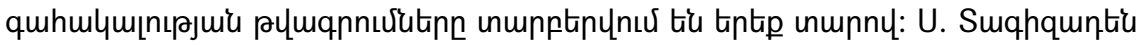

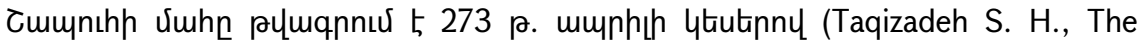
Early Sasanians. Some Chronological Points which Possibly Call for Revision, BSOAS, vol. 11, 1943-1946, pp. 41-42; Taqizadeh S. H., Henning W. B., The Dates of Mani's Life, Asia Major, vol. 6, 1958, p. 116): Unu pumqnnuरu nunniunuर Guml 4. Upntiqntiun (Widengren G., Manichaeism and its Iranian Background, in CHI, ed. by E. Yarshater, Vol. 3 (2). p. 970): Ч. <tüüuqú ujn pnunumănt-

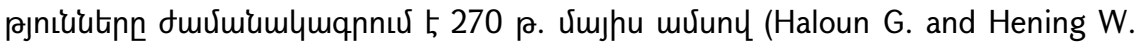
B., The Compendium of the Doctrines and Styles of the Teaching of Mani, the Buddha of Light, AM, vol. 3, 1952, pt. 1, p. 199): 4. <tühuqh 4undopn muzun-

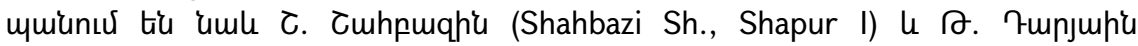

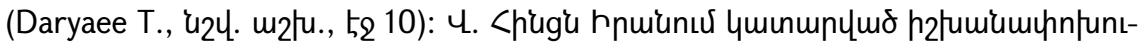
pjuí pululuiun huviumnus 5272 p. (Hinz W., Mani and Karder, in Atti del convegno internazionale sul tema la Persia nel medioevo (Roma, 31 marzo - 5 aprile 1970), Accademia Nazionale dei Lincei. Anno CCCLXVIII - 1971. Quaderno N. 160. Roma, Accademia Nazionale dei Lincei, quaderno 160, Rome, 1971, p.

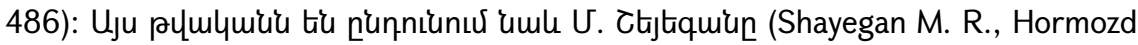
I, Elr, vol. XII, Fasc. 5, p. 462), Ч. Lnılnuhiun (Луконин В. Г. "Варахран II и 


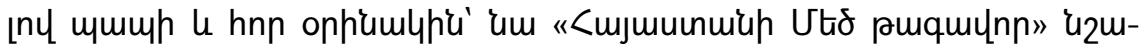
'umlitg hunuquien nnnniu' กnúhqnulyhu: กnưhqn I-

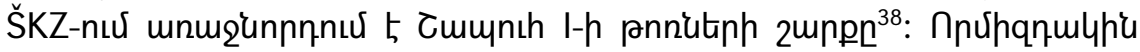

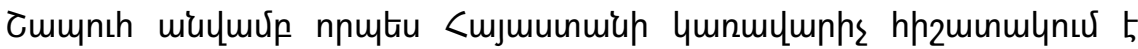

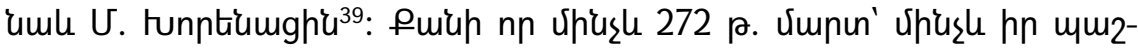

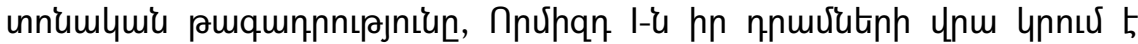

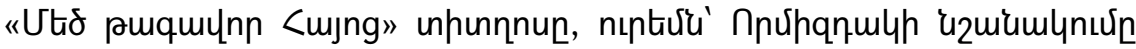

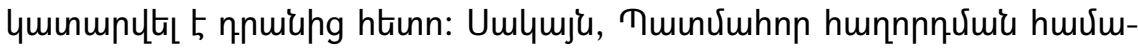

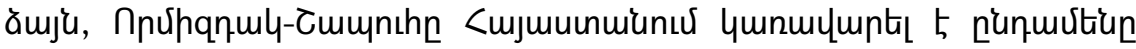

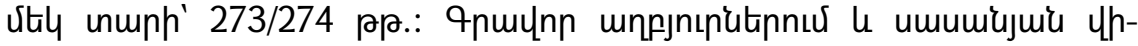

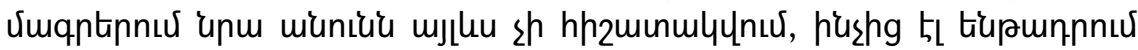

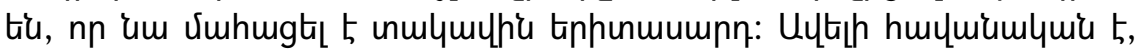

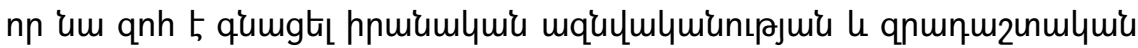

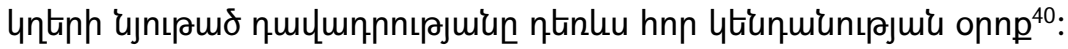

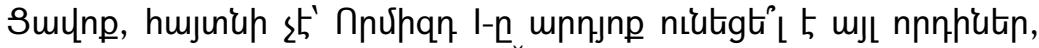

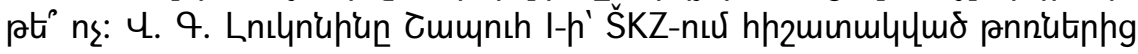

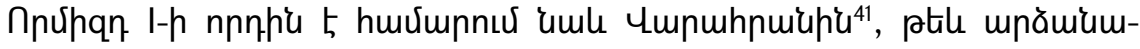

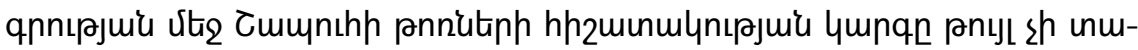

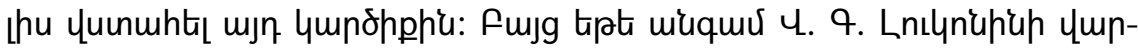

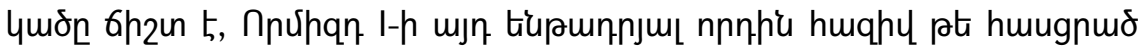

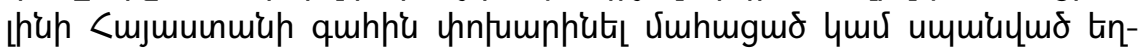

Hарсе". (Иран в 70-90-е годы III в.), Вестник древней истории, 1964, N 1, стр. 49), П. \$ршјц (Фрай Р. Н., Наследие Ирана, Москва, 2002, стр. 369, прим. 3), ๆ. 4ntjtiupnln (Kreyenbroek P.G., How Pious Was Shapur I?: Religion, Charch and Propaganda under the Early Sasanians, in The Sasanian Era: The Idea of Iran, Vol. III, p. 7), 4. Suиnfun (Фаррох К. "Персы. Армия великих царей". Москва, 2009, стр. 205) u uј!p:

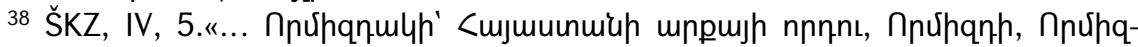

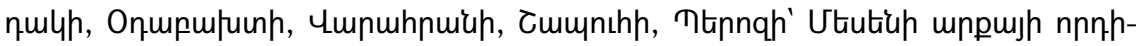
Utiph...» (Sprengling M., Third century Iran, Sapor and Kartir, Chicago, 1953, p.

18):

39 tunptiumgh U., II, <t:

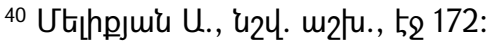

${ }^{41}$ Луконин В. Г. "Культура Сасанидского Ирана", стр. 103. 


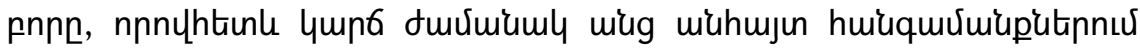

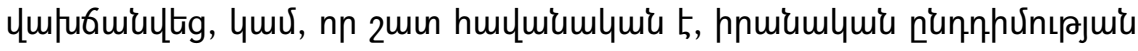

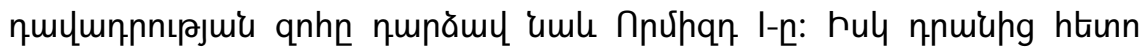

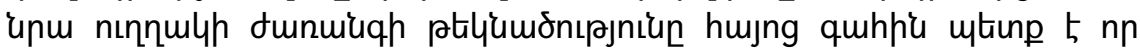

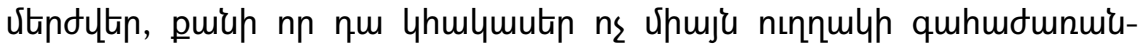

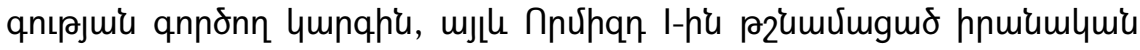

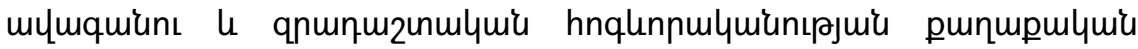
qopu:

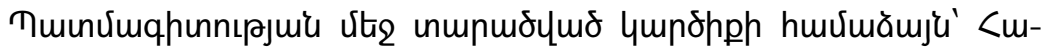

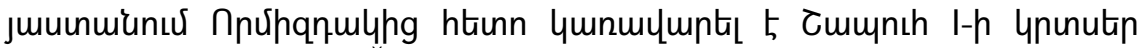

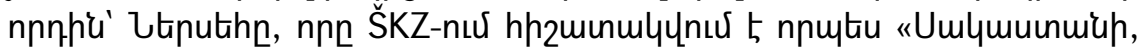

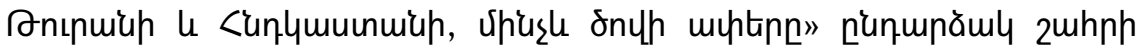

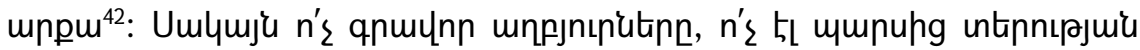

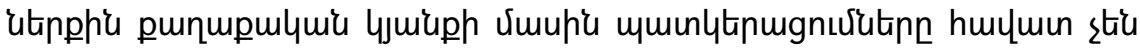

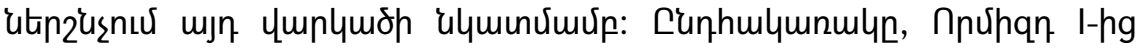

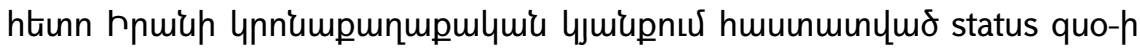

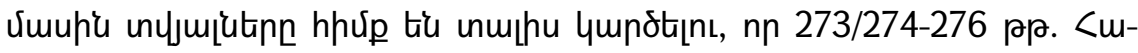

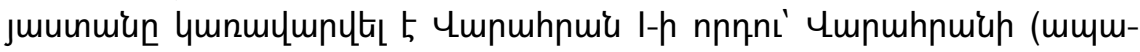

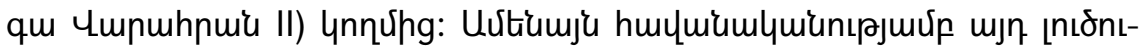

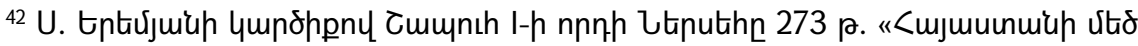

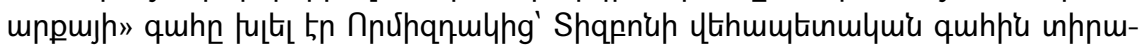

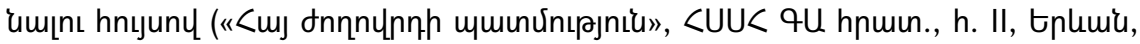

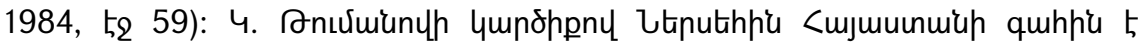
'uuuntignt, h'upn' npúhqn-Ununuzhnn, 273 p. (Toumanoff C., The Third Century Armenian Arshacids. A Cronological Commentary. Revue de sétudes Arméniennes. N VI, 1969, p. 257): U. Umpunpnnujuiun lu <mjuuunuiuh quhhiu nnúpqnulyh

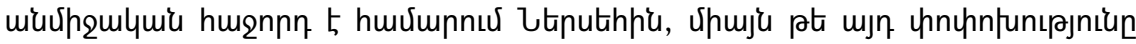

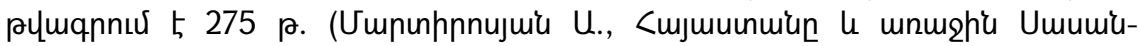

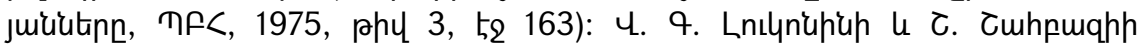

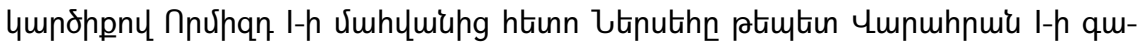

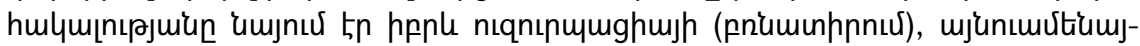

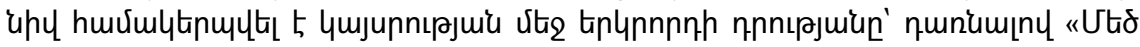
puquцnn <ujng» (Луконин В. Г., Варахран II и Нарсе, (Иран в 70-90-е годы III в.), стр. 48 и сл.. Shahbazi Sh., Bahrām I, Elr, 2012, Vol. III, Fasc. 5, pp. 514522): 


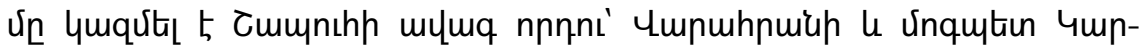

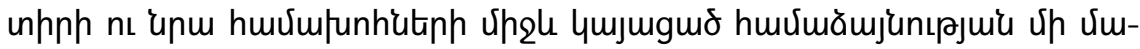

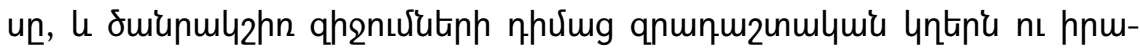

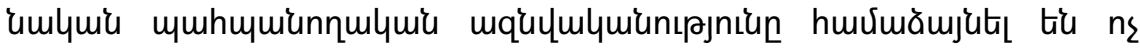

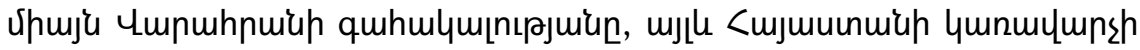

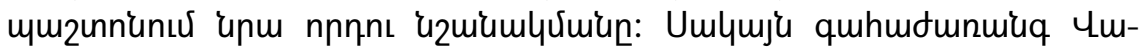

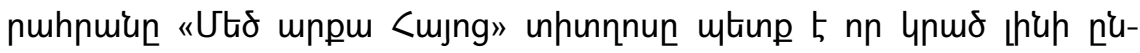
quivtiun un puiah unuph:

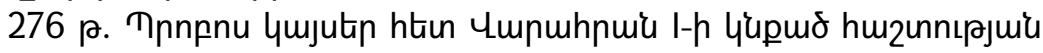

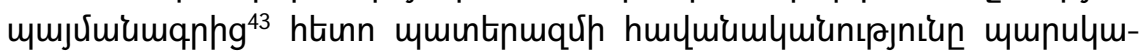

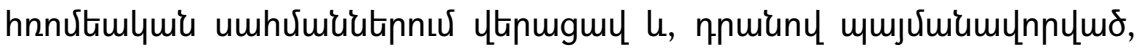

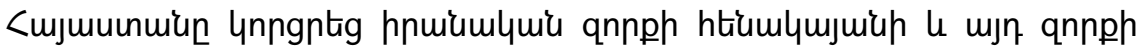

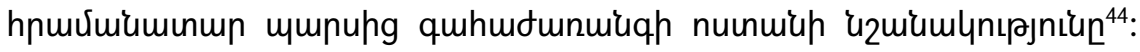

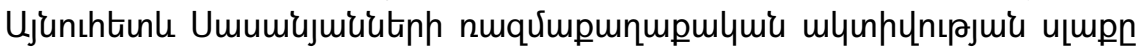

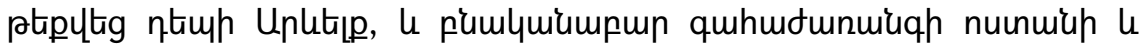

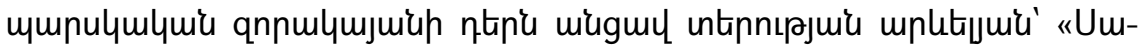

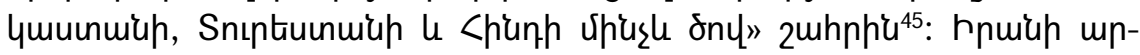

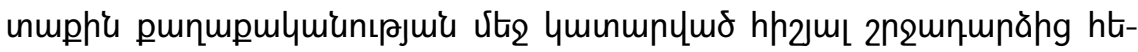

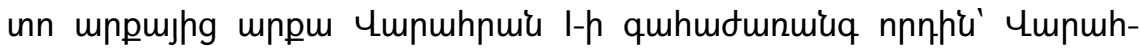

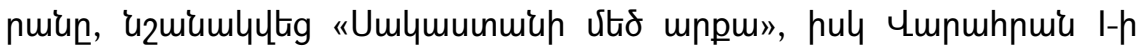

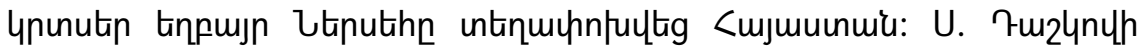

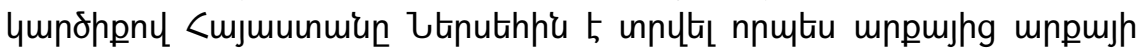

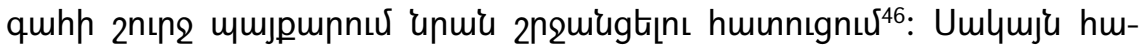

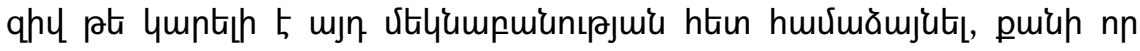

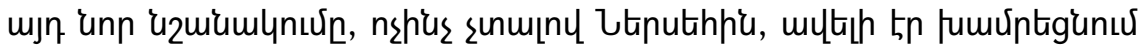

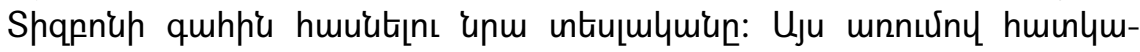

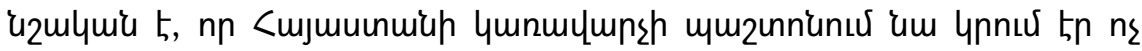

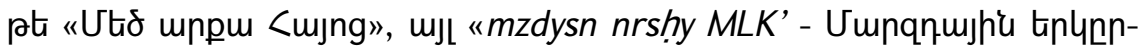

\footnotetext{
${ }^{43}$ Historia Augusta, with an English Translation by David Magie, Vol. I-III, London, VII edition, 1991, Prob. 17-18: tunntiumgh U., II, <L:

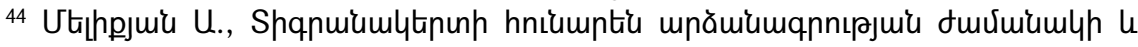

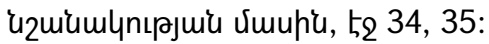

${ }^{45}$ Unıju untinnux:

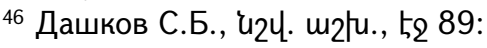




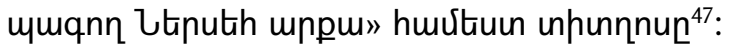

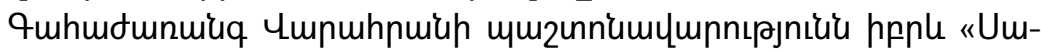

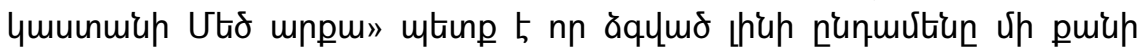

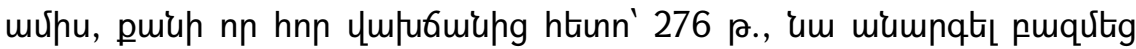

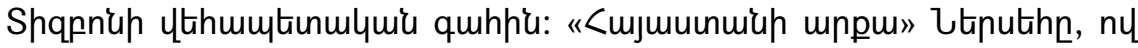

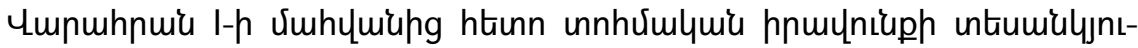

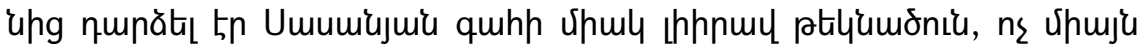

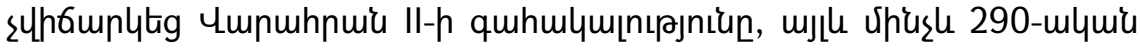

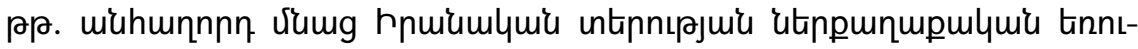

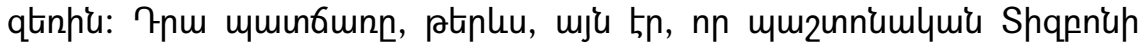

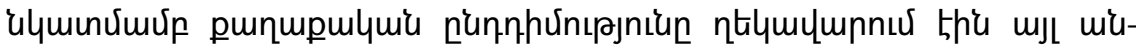

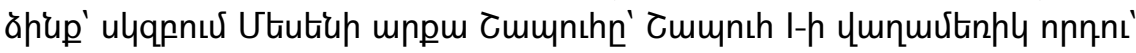

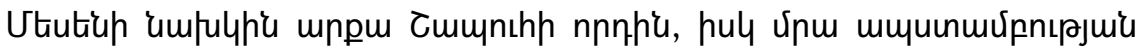

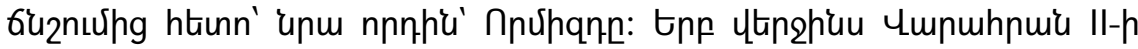

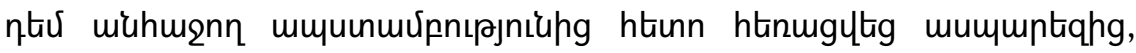

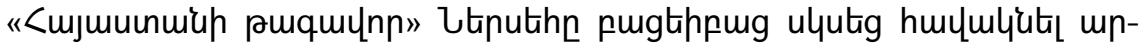

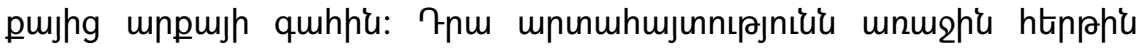

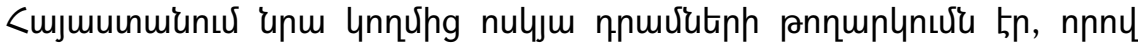

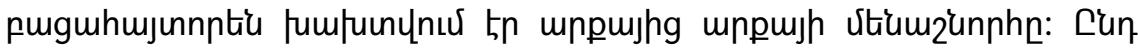

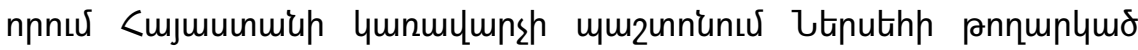

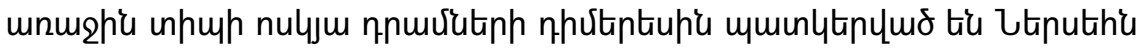

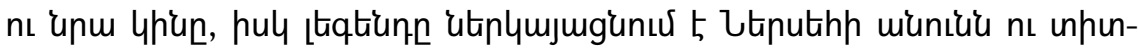

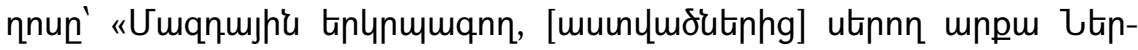

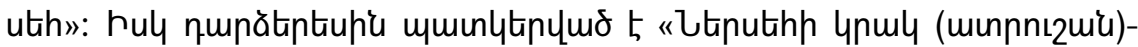

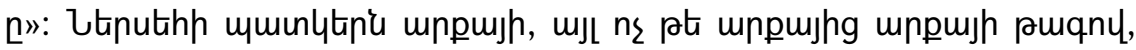

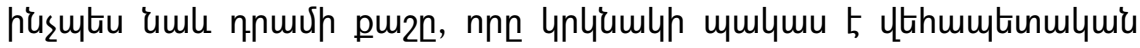

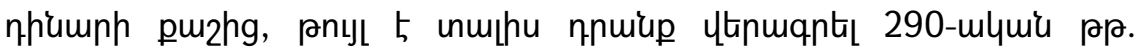

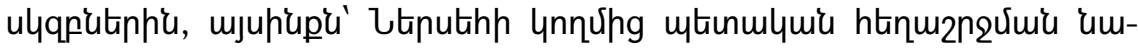

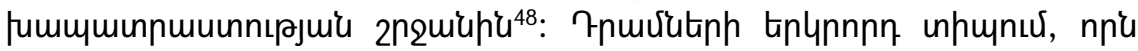

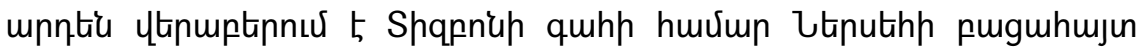

\footnotetext{
47 Луконин В. Г. "Культура Сасанидского Ирана", стр. 180.

48 Луконин В. Г. "Варахран II и Нарсе", стр. 57.
} 


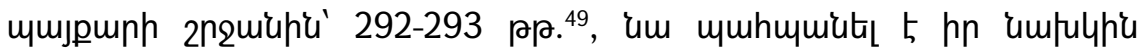

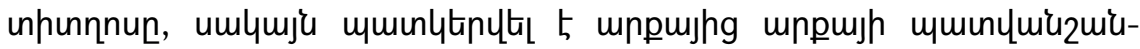

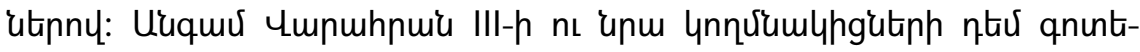

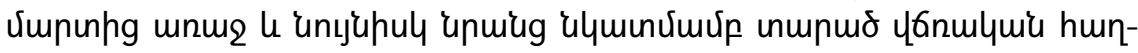

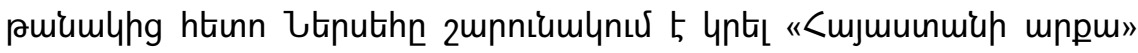

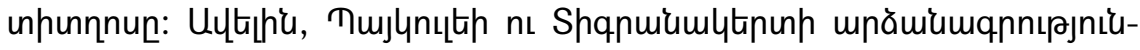

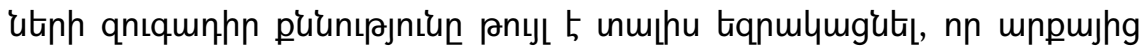

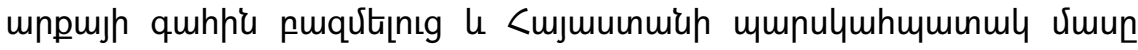

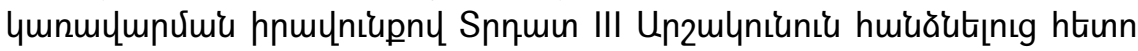

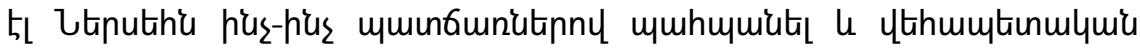

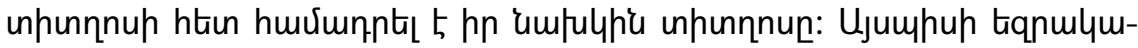

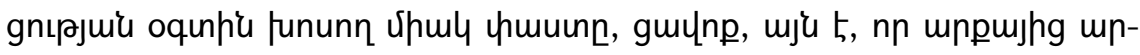

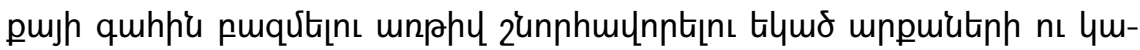

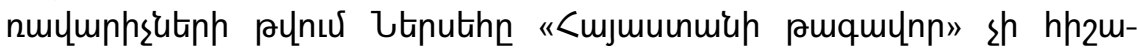
unuly4nux ${ }^{50}$ :

\section{MELIQYAN ARTHUR}

\section{ABOUT THE TITLE OF SASANYAN PRINCES RULED IN ARMENIA IN THE $3^{\text {RD }}$ CENTURY}

Our exploration shows that the ruling of Sasanyan crown princes in Armenia was one part of Sasanyan $1^{\text {st }}$ ruler's policy for solving the problem of the succession of the throne. Choosing the crown in the way of monopoly the Sasanyan king of kings did their best to srenghten their smart sets positions as much as they could. For the transferation of the throne they chose the types of iconography preaching used in earlier Achaemenid Empire with the military-administrative mechanisms used in Parthian empire. The title of "Great King of Armenian" given to the

\footnotetext{
49 Unıju untinnux:

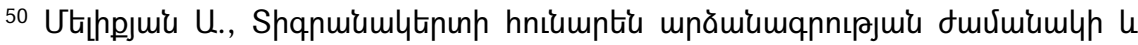

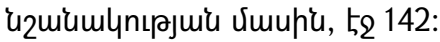


Sasanyan crown princes served the same aim.

In it "The Great King" had the honor's meaning which refered predominantly to the crown and, it also refered to Armenia in a way that with its boardering position it was the garden of the heir of crown prince and the central place for the army.

The role of Armenia in the Sasanyan administrative system was not static; it was conditioned with the west direction of the external policy of early Sasanian Empire. It was not by chance that in the militaryadministrative system of Sasanyan empire Armenia retained its role untill the sighning of the peace treaty between emperor Probus and Varahran the First in 276. After the mentioned treaty in 276-293 Nerseh, who ruled in Armenia, already bore not the title of "The Great King of Armenia" but the title of "The king of Armenian". 